\title{
Transition towards a green economy in Europe: Innovation and knowledge integration in the renewable energy sector
}

\author{
C. Conti ${ }^{\text {a }}$, M.L. Mancusi ${ }^{\text {b,*, }}$ F. Sanna-Randaccio ${ }^{\text {a }}$, R. Sestini ${ }^{\text {a }}$, E. Verdolini ${ }^{c}$ \\ a Department of Computer, Control and Management Engineering “Antonio Ruberti” (DIAG), Sapienza University of Rome, Italy \\ ${ }^{\mathrm{b}}$ Department of Economics and Finance, Università Cattolica del Sacro Cuore and ICRIOS (Bocconi University), Milan, Italy \\ ${ }^{\mathrm{c}}$ CMCC Foundation (Euro-Mediterranean Center on Climate Change), Milano, Italy
}

\section{A R T I C L E I N F O}

\section{JEL classification:}

Q55

Q58

Q42

O31

\section{Keywords:}

EU integration

Renewable energy technologies

Knowledge flows

\begin{abstract}
A B S T R A C T
This paper investigates the fragmentation of the EU innovation system in the field of renewable energy sources (RES) by estimating the intensity and direction of knowledge spillovers over the years 1985-2010. We modify the original double exponential knowledge diffusion model proposed by Caballero and Jaffe (1993) to provide information on the degree of integration of EU countries' RES knowledge bases and to assess how citation patterns changed over time. We show that EU RES inventors have increasingly built "on the shoulders of the other EU giants", intensifying their citations to other member countries and decreasing those to domestic inventors. Furthermore, the EU strengthened its position as source of RES knowledge for the US. Finally, we show that this pattern is peculiar to RES, with other traditional (i.e. fossil-based) energy technologies and other radically new technologies behaving differently. Our results provide suggestive, but convincing evidence that the reduction in fragmentation emerged as a result of the EU support for RES taking mainly the form of demand-pull policies.
\end{abstract}

\section{Introduction}

Technologies related to renewable energy sources (RES) have been at the top of $\mathrm{EU}$ and member states agendas since at least the end of the 1980s for compelling economic and environmental reasons. Over the years, they have been promoted as a way to diversify energy supply and to lower dependence from fossil fuel imports (The Council of the European Communities, 1986; EC, 2000), to reduce environmental and health pressure (HEAL, 2013) and to create new jobs and skills in progressive sectors with high growth potential (EC, 1997, 2006a). Recently, member countries committed to the transition towards a resilient Energy Union with a forward-looking, stringent climate policy, capable of delivering long-term climate and energy targets. As the recent Paris climate agreement (2017) testifies, in the EU promoting renewable energy is seen as a way to support sustainable development while boosting Europe's competitiveness and export potential, obtaining a comparative advantage vis-à-vis other top innovators such as the US and Japan (EEA, 2012; EC, 2014, 2015a).

At the end of the 1990s, a boost to RES came from the 1997 White Paper on renewable sources (EC, 1997). The EC specifically called for a Strategy and Action Plan to support renewable energy sources in light of the implementation of the Kyoto Protocol, of the increased commitment to reduce greenhouse gas emissions, and of the heterogeneous level of development and deployment in the member countries. ${ }^{1}$ According to the Commission, a coordinated and comprehensive approach was necessary to bring value added to national initiatives, ${ }^{2}$ increasing the overall impact both in the development and deployment of RES. In the following years, the EU implemented several demand-pull interventions aimed at creating a large and strong internal market for RES technologies. ${ }^{3}$ Among the key legislative and regulatory frameworks were the Directives establishing

\footnotetext{
* Corresponding author.

E-mail address: marialuisa.mancusi@unicatt.it (M.L. Mancusi).

${ }^{1}$ The share of renewable energies in gross inland energy consumption (GIEC) varied between less than 1\% in the UK to over 25\% in Sweden (see Table 1, EC, 1997).

${ }^{2}$ See IEA (2015c) for a list of policies at the national level.

${ }^{3}$ As explained in Cantner et al. (2016), demand-pull policies affect innovative activities indirectly by creating demand for cleaner technologies. These include for instance feed-in tariffs (FIT), or taxes on emissions. Conversely, technology-push policy measures are those measures that directly affect inventive and innovative activities in renewable energy sources. These include for instance direct public R\&D investments, as well as subsidies to research. Finally, systemic policies are those specifically meant to provide support for collaboration and knowledge transfer, such as cooperative R\&D programs, clusters or infrastructure provisions.
} 
national targets for renewable energy production from individual member states, ${ }^{4}$ and the 2005 EU Emission Trading System to curb carbon emissions. These demand-pull policies marked a significant shift in the promotion of renewable energy technologies, with member states acting in a much more coordinated way and with the EU steering the development of a community policy (EC, 2006b). Yet, in 2013, fossil fuels still accounted for more than $80 \%$ of the EU's GIEC (EEA, 2016). Indeed, much remains to be done to further support the energy transition, especially in the development of frontier carbon-free technologies (IEA, 2015b).

A major concern in this respect is the fragmentation of the EU innovation system (EC, 2010; Fischer et al., 2009; LeSage et al., 2007). Similarly to the arguments supporting the creation of a single market, an integrated EU innovation system was promoted as a way for EU countries to benefit from their neighbours, on the assumption that more integrated research efforts would give rise to a virtuous circle, reducing the duplication of research efforts and allowing each country to learn and benefit from the knowledge of other members. Conversely, a disparate and fragmented research and development effort would translate into an "insufficient capacity to innovate, to launch new products and services, to market them rapidly on world markets and, finally, to react rapidly to changes in demand" (EC Green Paper on Innovation, 1995).

In the specific case of renewable energy technologies, several analyses demonstrate that the introduction of demand-pull measures provided incentives to RES innovation and deployment (Corsatea, 2014; Borghesi et al., 2015; Cantner et al., 2016; Nicolli and Vona, 2016; Noailly and Shestalova, 2017). However, fragmentation remains one of the most crucial concerns, potentially delaying, or even impeding, the achievement of the ambitious EU climate targets (EC, 2007, 2015b). For instance, in 2006 the EC called for the establishment of a EU Strategic Energy Technology Plan, recognizing past efforts in RES research and development, but claiming a still "scattered, fragmented and sub-critical" RES innovation space, which needed greater integration and coordination of Community and national research and innovation programs and budgets, under the aegis of agreed EU-level goals (EC, 2006b). Thus, a less fragmented EU RES innovation system is believed to be instrumental to exploiting the federating role that the European Union can play in the field of energy and to meet the challenge of developing a world-class portfolio of affordable, competitive, efficient and low-carbon technologies while creating stable and predictable conditions for industry (EC, 2006b). Along similar lines, in a later communication the European Commission argues that "the fragmentation, multiple non-aligned research strategies and sub-critical capacities that remain a prevailing characteristic of the EU research base" are critical factors constraining EU firms' innovative capability (EC, 2007).

The concern of European policy makers is in line with the view of several theoretical (e.g. De Bondt et al., 1992; De Bondt, 1996; Levin and Reiss, 1988) and empirical (e.g. Cassiman and Veugelers, 2006; Mancusi, 2008; Peri, 2005; Verdolini and Galeotti, 2011) studies supporting the argument that a fragmented knowledge space hinders knowledge flows and, consequently, spillovers in the geographical space, thus suppressing opportunities for further innovations and hindering the movement towards the technological frontier. A central tenet of this approach is that the innovative output of firms and countries is driven not only by own R\&D efforts, but also by the assimilation of external knowledge, which in turn crucially depends on the absorptive capacity of the recipient. Since this is determined by the recipient's own research efforts (Cohen and Levinthal, 1989), a higher intensity of knowledge flows translates into higher benefits when coupled with own

\footnotetext{
${ }^{4}$ Indicative targets were adopted under Directive 2001/77/EC. Although the EU was not meant to strictly enforce these targets, the European Commission monitored the progress of the Member States and could, if necessary, propose mandatory targets for those who missed their goals. Later, Directive 2009/28/ EC set mandatory targets for member states. See also IEA (2015c) for a list of other policies at the EU level.
}

research efforts. Contrary to this well-accepted view, some contributions argue that increased cross-country knowledge flows might lead to some countries free-riding on foreign research, with a negative impact on innovation (see e.g. Garrone and Grilli, 2010; Grafström, 2017). Such line of reasoning, which emphasizes the disincentive effect of imperfect appropriability, is supported by relatively little empirical evidence. ${ }^{5}$ Although our paper focuses on knowledge flows and not directly on knowledge spillovers, which are the (positive or negative) effects of knowledge flows on innovation output, our evidence, coupled with the innovation performance of the EU in RES technologies, is in line with the prevailing view, and hence with policy concerns, on the detrimental role of fragmentation.

This paper thus contributes to the literature by investigating the fragmentation of the EU innovation system in the field of renewable energy sources. This crucial aspect of renewable energy innovation dynamics has not received attention to date. Understanding how knowledge flows among EU countries and between the EU and other top innovators have evolved over time is important because it can shed light on the effectiveness of past actions and policy support to promote RES development and the integration of the RES innovation space in the $\mathrm{EU}$, as well as drive future policies in this respect.

We analyse the intensity and direction of intangible knowledge flows over the years 1985-2010 using information on patent applications and citations at the European Patent Office (EPO). Our focus is on the three main innovating regions of the world: the US, Japan and the EU15, which together account for roughly $87 \%$ of innovation in this field in our sample. In line with a rich literature on similar subjects, we follow the paper trail left by within-country and cross-country patent citations, using citation frequencies to explore the patterns of knowledge flows within the EU and between the EU and other top innovators. We modify the original double exponential knowledge diffusion model of Caballero and Jaffe (1993) and Jaffe and Trajtenberg (1999) to provide information on the degree of integration of EU countries' innovative efforts and to assess how citation patterns changed over time.

We show that indeed EU RES inventors have increasingly built "on the shoulders of the other EU giants", intensifying their citations to other member countries and decreasing those to domestic inventors. We show that these effects are not driven by Germany, the EU top innovator, nor are they simply the result of increased collaboration in patenting or of an increase in patent quality. Furthermore, we find that the EU strengthened its position as source of RES knowledge for the US. We also compare RES to other relevant technologies in order to gain evidence on whether the observed patterns are common to other technology fields. We start by considering fossil-based energy technologies. Only a few contributions in the literature study both RES and other types of energy generation (Dechezleprêtre et al., 2013, 2014; Verdolini and Bosetti, 2017; Verdolini et al., 2018), but they address research questions that are different from the one we focus on. We then compare RES to a set of emerging technologies (3D, IT, Biotechnologies and Robot technologies), as in Dechezleprêtre et al. (2014), to assess if our results are specific to RES or common to booming technologies at an early stage of development. We show that the pattern of knowledge flows and its evolution in time is peculiar to RES, with traditional (i.e. fossil-based) energy technologies and other new technologies behaving in a completely different way.

Our results support the claim that the EU reduced the fragmentation of the innovation space specifically in the field of RES over the sample period. Our analysis thus presents suggestive, but convincing evidence that the reduction in fragmentation was brought about by the strong

\footnotetext{
${ }^{5}$ This approach has found little support also on the theory side. For example, Park (1998) investigates whether, in the presence of international spillovers, governments would free-ride on foreign research and thus conduct less R\&D. His model interestingly accounts for absorptive capacity and finds that governments will not follow this path.
} 
support of the EU to climate mitigation and renewable energy technology development vis-à-vis the laxer effort put forward by the US and Japan in this respect. We conclude by highlighting the need and scope for further integration.

The rest of the paper is organized as follows. Section 2 presents our proxy for knowledge spillovers along with a brief literature review on the topic. Section 3 describes our sample and provides descriptive evidence of the recent surge in renewable energy innovation in the EU and of changes in the patterns of knowledge flows. Section 4 describes in detail the empirical model we use to corroborate such evidence and the empirical hypotheses we test. Section 5 presents main results and Section 6 focuses on robustness checks. Finally, Section 7 concludes and presents some policy implications.

\section{Knowledge flows and integration}

Knowledge flows may occur through different channels. They may be embodied into goods or people, or rather they can be disembodied. Indeed, a large part of the literature on knowledge flows has focused on the latter. ${ }^{6}$ Our analysis also focuses on disembodied knowledge transfer and employs patent citations as indicators of knowledge flows in RES technologies. This approach has a long tradition in the literature and itself relies on the use of patent data to assess the innovative effort of firms, sectors and countries. Patents are indeed the only available indirect evidence of innovative activity offering a detailed breakdown by technology for a large number of countries and for long time series. Furthermore, patent documents include references to previous patents (citations), providing information on the sources of knowledge that were relevant for the conception of the new invention. Although citations are widely employed in the literature, it should be mentioned that there are alternative indicators of disembodied knowledge flows. For instance, knowledge transfer can be traced also by considering the size and structure of co-inventor networks (e.g. Cantner et al., 2016) or university-industry research collaborations (e.g. Balconi et al., 2004).

Relying on patent and citation data to proxy for innovation and knowledge flows, respectively, has shortcomings, but also significant advantages. ${ }^{7}$ In particular, Jaffe et al. (1993) argue that patent citations can be interpreted as "bits" of previous knowledge that were relevant in the development of the new knowledge contained in the citing patent. Although citations can at best capture flows of codifiable (vs. tacit) knowledge, they still provide insights on how knowledge may diffuse within and across geographical regions and technological fields (see e.g. Mancusi, 2008), and how the resulting patterns may change over time. This has been confirmed using data from the US Patent Office (USPTO) in Jaffe et al. (1998), but also (and importantly for our analysis) using data from the European Patent Office (EPO) in Duguet and MacGarvie (2005) and Bacchiocchi and Montobbio (2010).

Early econometric studies use patent citations to examine the factors enhancing or hindering knowledge flows, with special attention to the role of geographical distance and boundaries, and to compare local (national) with international knowledge diffusion. These studies conclude that geographical distance, national borders, language and institutional distance reduce the intensity of knowledge flows (Bottazzi and Peri, 2003; Peri, 2005; Maurseth and Verspagen, 2002). Furthermore, knowledge flows are more intense and effective when occurring within rather than across technological fields (Jaffe and Trajtenberg, 1999; Mancusi, 2008).

Some other studies focus on the direction of cross-country

\footnotetext{
${ }^{6}$ External accessible disembodied knowledge has been found to have a significant positive effect on TFP (Lee, 2006) and on local innovation production (Mancusi, 2008) and there is evidence that such effect might be even stronger than that of embodied knowledge (Drivas et al., 2016).

${ }^{7}$ See Griliches (1990) and Jaffe et al. (1993) for extensive discussions on this point.
}

knowledge diffusion. Among these, in particular, Hu and Jaffe (2003) examine North-South patterns of knowledge diffusion from the US and Japan, on the one side, to Korea and Taiwan, on the other side. Hu (2009) estimates the citation intensity between East Asian countries, Japan and the US. His findings of a tight net of cross-country flows within East Asia are interpreted as a measure of integration of the innovation systems within that area and thus support the hypothesis of an increasing regionalization of knowledge diffusion within East Asia. ${ }^{8}$

Most of the studies cited above have been largely motivated by the growth and convergence effects associated with knowledge flows and their spillover effects. Indeed, a wide literature has maintained that the diffusion of knowledge generates positive externalities because knowledge flows increase the productivity of R\&D. The positive externality arises due to complementarities in R\&D efforts by firms and countries, which is associated with the notion of absorptive capacity (Cohen and Levinthal, 1989; Aghion and Jaravel, 2015), namely the idea that knowledge created by competitors can be exploited only through own R\&D. Thus, knowledge spillovers may increase equilibrium R\&D investment (Antonelli and Colombelli, 2017). An alternative and somewhat more traditional view attaches little importance to absorptive capacity and emphasizes that knowledge spillovers reduce incentives to invest in R\&D due to the inability to fully appropriate its returns, thus leading to underinvestment in own R\&D.

This second view has been of particular concern in recent studies on the renewable energy sector (Jaffe et al., 2005; Popp, 2005; Grafström, 2017), where underinvestment would hamper the ability to achieve the necessary carbon emissions reductions needed to address climate change. In particular, with reference to the European Union, the paper by Grafström (2017) raises the concern that increased cross-country knowledge flows might induce some countries to free-ride on foreign research, with a negative impact on innovation, but finds limited empirical support to this hypothesis. By contrast, the view of a positive impact of spillovers on innovative output discussed above finds support in a large number of studies associating knowledge flows with higher innovation output in a broad variety of sectors, including RES technologies (Verdolini and Galeotti, 2011).

Given the existing empirical evidence, concerns about the high degree of fragmentation of the EU innovation system (Fischer et al., 2009; LeSage et al., 2007) and the call for a higher integration in the RES knowledge bases of EU countries clearly reside on the widely-shared view that increasing the intensity of knowledge flows across EU states can broaden and deepen their technological base, leading to opportunities for further innovations and possibly to a movement towards the technological frontier. However, to our knowledge, there are no studies dealing directly with the fragmentation of the EU renewable energy innovation system and its changes over time. ${ }^{9}$

To fill this gap in the literature, we look for evidence on the degree of integration of national knowledge bases across the EU, while still accounting for knowledge flows between the EU and other technological leaders (Japan and the US). We estimate the probability of citation within and between EU15 countries, US and Japan in the clean energy sector as a measure of the intensity of knowledge flows across countries. Similarly to Hu (2009), we design the model so that we can interpret the results for the EU as providing information on the degree of integration of EU countries' innovation efforts. Also, following Popp (2006), we modify the original double exponential model to assess how citation patterns changed over time.

\footnotetext{
${ }^{8}$ Another interesting paper is that by Wu and Mathews (2012), who investigate knowledge flows from advanced countries (US, Japan and Europe) to follower countries (Taiwan, Korea and China) in the solar photovoltaic industry.

${ }^{9}$ Cantner et al. (2016) studies the effect of different policy instruments on the size and structure of co-inventor networks based on patent data, but does not distinguish between foreign and domestic inventors.
} 


\section{Data and descriptive evidence}

We use data on patent applications from the PATSTAT-CRIOS database. ${ }^{10}$ In particular, we focus on patent applications at the European Patent Office (EPO) in RES technologies (hydro, solar, wind, biomass, geothermal, ocean, and waste), which we identify using International Patent Classification (IPC) codes, as proposed by Johnstone et al. (2010) and reported in Appendix A1 (in Supplementary material). We consider applications by inventors ${ }^{11}$ residing in the EU15, ${ }^{12}$ US and Japan over the years 1985 to 2010 . Each patent is assigned to a year depending on its priority date, i.e. the date closest to the innovation. To account for changes in the intensity and direction of knowledge flows, we split our sample in two periods: the first half covers the period 1985-1999, while the second half ranges over 2000-2010. We refer to the two periods as pre-2000 and post-2000, respectively. We choose 2000 as the first year of the second period in view of the acceleration in EU renewable energy patenting at the turn of the century (see Fig. 1). As already noted such acceleration took place a few years after 1997, the year in which the Kyoto protocol was adopted and the Commission White Paper "Energy for the Future: Renewable Sources of Energy" was released, indicating an increased commitment of the EU to decarbonize its energy sector.

Overall, our sample includes 23,162 patent applications, $62 \%$ of which belong to EU15 inventors while the US and Japan account for 20 and $18 \%$, respectively (see Table 1 ). The particularly high number of EU15 patents relative to US and Japanese patents in our sample is due to two main reasons. First, since we are using EPO patent data, our statistics reflect a home bias effect in favor of European countries at the EPO. This pattern, which has to be kept in mind when looking at the descriptive statistics shown in Table 1 and in Fig. 1 and which also emerges in other studies, ${ }^{13}$ will be fully addressed and controlled for in our empirical estimation. Second, around 50\% of EU15 innovation in RES over the whole sample period is accounted for by Germany, which has historically been a top innovator. We return on this last point in Section 4.

RES EPO patents by the US, Japan and EU15 are characterized by an upward trend, with the turn of the century marked by a considerable increase in the growth rate of patent applications in all three geographical areas (see Fig. 1). However, EU15 RES patents increased at a

\footnotetext{
${ }^{10}$ See Coffano and Tarasconi (2014) for a detailed description of the data.

${ }^{11}$ Patents are assigned to the inventor's country rather than the assignee's country, as it is customarily done in the patent literature, in order to attribute the patent to the location where the innovation has indeed been developed. Nevertheless note that, since our countries are all well developed countries, this has no implications for our analysis as patent counts by inventor country and by assignee country are almost identical (see also Sung et al., 2014).

${ }^{12}$ The choice to focus on EU15 countries is mainly driven by the very low count of RES patents in other EU countries. Note, however, that this does not represent a limitation of our analysis because EU15 RES patents represent 99\% of EU27 RES patents over our sample period: should we include the additional $1 \%$ of patents in our regression analysis, they would contribute extremely little to the identification of parameters of interest. Therefore, we decided to focus on the largest set of European countries where most of the innovation effort and results actually occur. Furthermore, this is also the set of EU member countries as of 1995 and until 2004. Given our aim to find suggestive evidence of the role of EU environmental policy commitment on knowledge integration after 2000, limiting the analysis to EU15 countries also seems appropriate.

${ }^{13}$ The issue of home country bias is common in studies which rely on patent as a proxy of innovation. For instance, many studies use statistics on the USPTO, which also represent patents by US inventors much more frequently than patents from inventors from other countries. A pattern similar to ours also emerges in Johnstone et al. (2010) where Germany, followed by US and Japan, exhibits the highest number of patents and a surge in patenting activity after 1997 (see Fig. 2, p. 141). This is admittedly due to some extent to the presence of home bias when using EPO applications. The same effect is highlighted in OECD (2012) pp. 23-24.
}

particularly high rate: while they accounted for 53\% in 1985, their share was up to $67 \%$ by 2010 . This acceleration in EU15 RES innovation came about close after 1997, the year of the adoption of the Kyoto Protocol and of the release of the European Commission White Paper on renewable sources (EC, 1997). As discussed in the introduction, the turn of the century marked a period of increased commitment of the EU to decarbonize its energy sector, providing a strong stimulus for renewable energy generation and calling for significant investment in RES electricity production. In addition to promoting the deployment of RES, the strong EU commitment also resulted in significant incentives to innovation, which increased in the member countries.

Focusing on pure patent counts only provides partial insights into innovation dynamics. For example, the higher growth rate of European applications in RES technologies with respect to the two most technologically advanced countries does not necessarily imply a movement of the EU towards the technological frontier. As pointed out in a rich literature (see for instance Griliches, 1990), patent statistics are only an imperfect proxy of innovation, and do not necessarily inform on the quality of inventions. Indeed, further insights on patent quality can be gained by looking at the average number of patent citations a RES patent receives from subsequent RES patents (so-called forward citations), which is also reported in Table $1 .{ }^{14}$ Forward citations are often taken as an indicator of patent quality/relevance. ${ }^{15}$ In this respect, note that US RES patents receive more citations than patents from the EU15 and Japan, on average, which is indeed not surprising, as the US is historically the frontier innovator. Furthermore, note that while the average number of forward citations received by US and EU15 patents before 2000 is very similar to (or possibly larger than) those received after 2000, the average number of forward citations received by Japan decreases in the second sub-period, possibly indicating an overall worsening of the quality of Japanese RES innovation.

We then focus on citations made by RES patents to previous RES patents (the so-called backward citations). As discussed in Section 2, backward citations are a widely used indicator of knowledge flows between a source (the cited patent) and a destination (the citing patent). We therefore use information on backward citations to trace knowledge flows across our three geographical areas of interest. Furthermore, as we are interested in exploring the extent to which EU countries source knowledge from themselves or from other EU members, we consider separately national citations (citing and cited patent belonging to the same EU15 country) and citations to other EU15 countries (citing and cited patent belonging to distinct EU15 countries). As customary in this type of studies, self-citations (i.e. citations to previous patents held by the same applicant firm) are excluded from the dataset in order to capture only true knowledge flows (Jaffe et al., 1993).

Table 1 shows that, over the whole sample period, US inventors

\footnotetext{
${ }^{14}$ To provide comparison between citations received by older as opposed to younger patents, we calculate the statistics on forward citations per patent limiting our attention to citations received within 4 years from the year of first application, which captures the majority of citations received by each patent (Jaffe and Trajtenberg, 1999). Note that our econometric model controls for the citation lag, as we discuss in Section 4.

${ }^{15}$ While measuring the quality of the innovation output is certainly a complicated matter, forward patent citations have been often used in the literature to this end. Indeed, forward citations (i.e. the citation that a patent receives from following patents) provide an indication that subsequent innovation was building on the knowledge embodied in the original patent. Hence, the higher the number of forward citations a patent receives, the more its knowledge content has spurred further knowledge developments, which implicitly suggests the original patent represents a significant inventive step with respect to existing knowledge (Harhoff et al., 2003). Note that we exclude self-citations (i.e. citations to previous patents held by the same applicant firm) from counts of forward citations, as they might reflect a deepening of firms' innovation along their current technological trajectories rather than quality.
} 


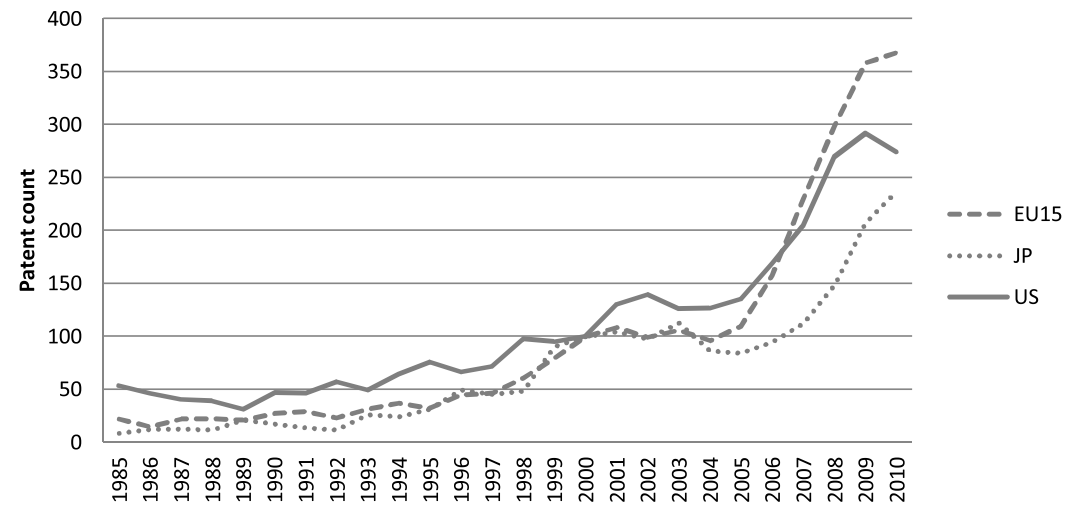

Fig. 1. Index of RES technologies patenting, EU15, US and Japan, $2000=100$.

Table 1

Descriptive Statistics.

\begin{tabular}{|c|c|c|c|c|c|c|c|c|c|}
\hline \multirow[b]{2}{*}{ Country } & \multicolumn{3}{|l|}{ Patents } & \multicolumn{3}{|c|}{ Forward Citations/patent } & \multicolumn{3}{|c|}{ Backward Citations/patent } \\
\hline & $1985-2010$ & pre-2000 & post-2000 & $1985-2010$ & pre-2000 & post-2000 & $1985-2010$ & pre-2000 & post- 2000 \\
\hline EU15 & 14,263 & 2,888 & 11,375 & 0.84 & 0.78 & 0.85 & 0.91 & 0.46 & 1.02 \\
\hline JP & 4,169 & 980 & 3,189 & 0.92 & 1.21 & 0.83 & 0.84 & 0.56 & 0.92 \\
\hline US & 4,730 & 1,464 & 3,266 & 1.29 & 1.16 & 1.35 & 1.15 & 0.59 & 1.41 \\
\hline Total & 23,162 & 5,332 & 17,830 & 0.94 & 0.96 & 0.94 & 0.94 & 0.51 & 1.07 \\
\hline
\end{tabular}

Table 2

Percentage distribution of citations, pre-2000 and post-2000.

\begin{tabular}{|c|c|c|c|c|c|c|c|c|c|c|c|}
\hline \multicolumn{12}{|c|}{ Renewable Technologies } \\
\hline & & \multicolumn{4}{|c|}{ pre-2000 } & & & \multicolumn{4}{|c|}{ post-2000 } \\
\hline \multirow[t]{2}{*}{ Cited country } & & \multicolumn{2}{|c|}{ EU15 } & \multirow[t]{2}{*}{ JP } & \multirow[t]{2}{*}{ US } & \multirow[t]{2}{*}{ Cited country } & & \multicolumn{2}{|c|}{ EU15 } & \multirow[t]{2}{*}{ JP } & \multirow[t]{2}{*}{ US } \\
\hline & & Nat & otherEU & & & & & Nat & otherEU & & \\
\hline \multirow[t]{3}{*}{ Citing country } & EU15 & 0.33 & 0.25 & 0.10 & 0.32 & Citing country & EU15 & 0.32 & 0.44 & 0.10 & 0.14 \\
\hline & JP & \multicolumn{2}{|c|}{0.27} & 0.29 & 0.44 & & JP & \multicolumn{2}{|c|}{0.26} & 0.61 & 0.13 \\
\hline & US & \multicolumn{2}{|c|}{0.34} & 0.12 & 0.54 & & US & \multicolumn{2}{|c|}{0.41} & 0.17 & 0.42 \\
\hline
\end{tabular}

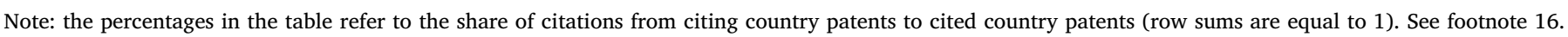

seem to be those relying more on previous knowledge: average backward citations per patent for the US is 1.15 , which is roughly $26 \%$ (37\%) more than EU15 (Japanese) patents. Table 2 presents the percentage distribution of backward citations across the different citing and cited geographical areas in the pre-2000 and post-2000 periods. ${ }^{16}$ These raw citations shares offer a preliminary indication that the direction of RES knowledge flows changed between the two periods, pointing to a strengthening of the EU as a source of knowledge both for domestic and foreign innovators. Specifically, three distinct patterns emerge. First, over the two periods the percentage of citations across distinct EU15 countries (otherEU) increased considerably. Second, the percentage of US national citations decreased, while the percentage of citations from the US to EU15 countries increased. Third, Japan seems to rely more on its own knowledge during the second period, but the

\footnotetext{
${ }^{16}$ The shares compare the backward citations of patents filed before 2000 with the backward citations of patents filed after 2000 in the following way: the numerator is the count of citations made by patents filed by inventors in region $i=U S, J P, E U 15$ between 1987 and 1997 (resp., 2000 and 2010) to patents of region $j=U S, J P, E U 15, E U_{\text {nat }}, E U_{\text {otherEU }}$ filed between the years 1987 and 1990 (resp., 2000 and 2003). The denominator is the total number of citations made by region $i$ over the same period (resp., 1987-1997 and 2000-2010). We fix the citing patent window and the cited patent window while computing the statistics as a way to provide comparable statistics across the two periods.
}

share of citations to EU15 patents did not decrease significantly.

All in all, the descriptive evidence presented in this Section points to a more prominent role of EU countries as source of knowledge for other EU member states, and thus to a strengthening of knowledge flows within the EU space. This could suggest a reduction in the fragmentation of the EU RES innovation system. However, any conclusion drawn from simply comparing raw citation shares may be misleading because these shares suffer from theoretical and actual biases. First, citations shares are determined by both the citation frequency (i.e. the probability of a patent from the citing country citing a patent from the cited country) and the overall level of patenting. Second, citations are always subject to truncation bias. As Brahmbahatt and Hu (2009) emphasize, raw citation shares inform on the gross flow of knowledge between two countries, but say little about the intensity of knowledge relationships. In order to examine that, citation frequencies need to be properly modeled. In the next section we detail our empirical strategy, which is designed to specifically address this concern and control for the confounding factors cited above.

Finally, a small fraction of patents in our sample (about 8\%) are assigned to inventors from more than one country. Since we are interested in citation frequencies as a measure of the link between country pairs, we retain such patents in our sample to account for every possible connection between countries. However, note that the number of patents with inventors from different EU countries increased from 4 to $8 \%$ of EU patents 
Table 3

RES patents with more than one inventor from different countries.

$$
\text { RES Technologies }
$$

\begin{tabular}{lll}
\hline & pre-2000 & post-2000 \\
\hline co-patenting EU15-EU15 on total EU15 patents & 0.04 & 0.08 \\
co-patenting EU15-US on total US patents & 0.20 & 0.17 \\
co-patenting EU15-JP on total JP patents & 0.00 & 0.03
\end{tabular}

Note: the values in the first row are computed as the mean, over each period, of the shares of RES patents with more than one inventor from different EU15 countries on total EU15 RES patenting. In the second (third) row there are the means, over each period, of the shares of RES patents with at least one inventor from US (JP) and one from EU15 countries on total US (JP) RES patenting.

in our sample (Table 3). This indeed raises doubts on whether the strengthening of knowledge flows between EU15 countries since 2000 may be due to "multiple-country" patenting within the EU. By contrast, note that the share of patents invented jointly by at least one US and one EU15 resident decreased from $20 \%$ of total US patents before 2000 to $17 \%$ since 2000. This seems to suggest that the higher intensity of citation from US patents to EU15 patents cannot be explained by changes in "multiplecountry" patents between the two regions.

\section{Empirical framework and hypotheses}

As discussed in the previous sections, our aim is to assess if the degree of fragmentation in the knowledge base of the European RES innovation system is high and whether a decrease in such fragmentation can be detected contextually with the increased EU support for RES in the form of demand-pull policies around the turn of the century. We do that by studying changes in the intensity of RES knowledge flows across the countries of interest through a double exponential knowledge diffusion model, proposed by Caballero and Jaffe (1993) and further developed by Jaffe and Trajtenberg (1996, 1999).

The model describes the random process underlying the generation of citations and allows estimating the parameters of the diffusion process while controlling for variations over time in the propensity to cite. It is designed to address truncation bias, a key feature of patent citations, which originates from the lower likelihood of citation of recent cohorts of patents with respect to older ones. More precisely, the knowledge diffusion process is modelled as follows:

$p_{i T j t}=\alpha(i, T, j, t) \exp \left[-\beta_{1}(T-t)\right]\left(1-\exp \left[-\beta_{2}(T-t)\right]\right)$

The dependent variable $p_{i T j t}$ is the expected frequency of citations, i.e. the likelihood that a patent from country $i$ first applied in year $T$ cites a patent from country $j$ first applied in year $t$. It is calculated in the sample as the following ratio:

$p_{i T j t}=\frac{C_{i T j t}}{\left(N_{i T}\right)\left(N_{j t}\right)}$

where $C_{i T j t}$ is the count of citations by country $i$ ' s patents with priority date $T$ to country $j$ ' s patents with priority date $t$, and $\left(N_{i T}\right)$ and $\left(N_{j t}\right)$ are respectively the number of potentially citing patents from $i$ at time $T$ and potentially cited patents from $j$ at time $t .{ }^{17}$ Citation frequencies are interpreted as an estimate of the probability that a randomly drawn patent in the citing group will cite a randomly drawn patent in the cited group. ${ }^{18}$

\footnotetext{
${ }^{17}$ The set of all RES patents, with or without citations, assigned to each country group in a given year alternatively represents the set of "potentially citing" patents or the set of "potentially cited" patents, depending on the citing and cited country in the unit of observation.

${ }^{18}$ Citation frequencies clearly abstract from the total number of applications by country $i$ and country $j$. Thus the relatively high number of patent applications from European countries that we have in our sample, and that is a
}

The expected frequency of citations is modelled as a combination of two exponential processes, one for the diffusion of knowledge and the other one for its obsolescence. Parameters $\beta_{1}$ and $\beta_{2}$ represent the rate of obsolescence and diffusion, respectively, and both exponential processes depend on the citation lag $(T-t)$.

In this framework, each $\alpha$ is a shift parameter that depends on the attributes of both citing and cited patents: a higher $\alpha$ means a higher probability of citation at all lags. We allow this proportionality factor to vary with the following attributes: citing year, cited year, and all possible combinations of citing and cited country pairs, i.e. $\alpha(i, T, j, t)=\alpha_{T} \alpha_{t} \alpha_{i j}$. Our main interest lies on $\alpha_{i j}$ : a higher $\alpha_{i j}$ means a higher probability of citation from $i$ to $j$ at all lags. Hence our estimated equation is:

$$
\begin{aligned}
p_{i T j t} & =\alpha_{T} \alpha_{t} \alpha_{i j} \exp \left[-\beta_{1}(T-t)\right]\left(1-\exp \left[-\beta_{2}(T-t)\right]\right)+\varepsilon_{i T j t}, i, j \\
& =E U 15, U S, J P
\end{aligned}
$$

In this type of models, the null hypothesis of no fixed effect corresponds to parameter values equal to one rather than zero for $\alpha_{i j}$ (as well as for $\alpha_{T}$ and $\alpha_{t}$ ). For each fixed effect, a group is omitted from estimation (i.e. its multiplicative parameter is constrained to unity), thus parameter values have to be interpreted relative to the base group. In our regressions, the base group for country pairs fixed effects $\left(\alpha_{i j}\right)$ is "US citing US", ${ }^{19}$ that is $\alpha_{U S, U S}=1$. This means that if, for example, $\alpha_{E U 15, U S}=0.8$, then a random EU15 patent is $20 \%$ less likely to cite a US patent than is a random US patent.

When focusing on citations within the EU15, we can distinguish between national citations (i.e. citations from any EU15 patent to patents from the same country) vs. international citations (i.e. citations from any EU15 patent to patents from a different EU15 country). Our parameter $\alpha_{E U 15, E U 15}$, which indicates the ceteris paribus propensity of EU15 patents to cite other EU15 patents, can then be split into two parameters: $\alpha_{E U 15, \text { nat }}$, which captures the average intensity of national citations within the EU15, and $\alpha_{E U 15, \text { otherEU }}$, which captures the average citation intensity between any EU15 country and all other EU15 members.

If fragmentation in the knowledge base of the European RES innovation system is indeed high, we should then observe a lower average propensity of European patents to source from local (European) knowledge compared to the US (i.e. the technological leader), coupled with an average higher propensity of each European country, itself off the technological frontier, to source from its own knowledge rather than from the knowledge base of its neighbours. This leads to our first hypothesis:

Hypothesis 1. Fragmentation of knowledge bases within EU is high compared to the technological leader:

$\alpha_{E U 15, E U 15}<\alpha_{U S, U S}=1 \quad$ and $\quad \alpha_{E U, n a t} \geq \alpha_{E U, \text { otherEU }}$

In order to verify if fragmentation decreases after year 2000, we modify model (2) to take into account changes in citation patterns over the sample period by allowing our shift parameters to change starting from 2000. We thus estimate the following equation:

$$
\begin{aligned}
p_{i T j t}= & \alpha_{T} \alpha_{t} \alpha_{i j}\left[1+\phi_{i j}{ }^{*} D_{2000}^{\text {citing }}\right] \exp \left[-\beta_{1}(T-t)\right]\left(1-\exp \left[-\beta_{2}(T-t)\right]\right) \\
& +\varepsilon_{i T j t}
\end{aligned}
$$

where $D_{2000}^{\text {citing }}$ is a dummy variable that takes the value of 1 when the

\section{(footnote continued)}

common feature of studies based on patents from a unique patent office, does not affect our estimates.

${ }^{19}$ As customary in this type of models, the citing year fixed effects $\left(\alpha_{T}\right)$ and the cited year fixed effects $\left(\alpha_{t}\right)$ are grouped into 2-year and 5-year intervals, respectively (see Jaffe and Trajtenberg, 1999; Popp, 2006; Bacchiocchi and Montobbio, 2010). The base group for citing year fixed effects $\left(\alpha_{T}\right)$ is 1985-1986 and for cited year fixed effects $\left(\alpha_{t}\right)$ is 1985-1989. 
citing patent's priority date is 2000 or later and $i, j=\mathrm{US}$, JP, EU15. This approach follows the one proposed in Popp (2006).

Our parameters of interest are now both $\alpha_{i j}$ and $\phi_{i j}$. The fixed effect $\alpha_{i j}$ indicates the relative likelihood that the average patent from country $i$ cites a patent from country $j$, while $\phi_{i j}$ captures the additional likelihood of citation between a pair of countries for citing patents with priority date 2000 or later. Note that, similarly to what discussed above for the $\alpha_{i j}$, also in the case of the $\phi_{i j}$ parameter one group is omitted from estimation, i.e. its multiplicative parameter is constrained, in this case, to zero. Thus $\phi_{i j}$ parameter values have to be interpreted relative to the base group, which is again "US citing US" $\left(\phi_{U S, U S}=0\right)$.

If country $i$ is increasingly taking advantage of technologies developed in country $j$ we should observe higher citation rates from $i$ to $j$ and interpret it as greater flow of knowledge from country $j$ to country $i$ in the second period. Hence, we can formulate our second hypothesis:

Hypothesis 2. Reliance of each European country on the knowledge base of other European countries increases after 2000:

$\phi_{E U 15, \text { nat }} \leq 0$ and $\phi_{E U 15, \text { otherEU }}>0$

Note that, if confirmed, hypothesis 2 does not yet necessarily suggest higher integration in the European RES innovation system. A first reason for this is that any changes in the post-2000 propensity to cite other EU countries may be driven solely by Germany, which, as explained in Section 3, accounts for 50\% of RES innovation in the EU15. Any aggregate trends such as the ones discussed so far could indeed be the result of Germany being a technological leader and thus a relevant source and an intensive user of foreign knowledge. Integration across the European RES technology space would instead imply an increasing intensity of knowledge flows across the remaining EU15 countries. We thus formulate the following

Hypothesis 3. Reliance of each European country other than Germany on the knowledge base of other European countries (other than Germany) increases after 2000:

$\phi_{E U 14, n a t} \leq 0, \quad \phi_{E U 14, \text { otherEU }}>0$

where EU14 refers to the group of EU15 countries, but Germany. We obtain such coefficients from Eq. (3) where $i, j=\mathrm{US}$, JP, DE, EU14.

A second reason why hypothesis 2 may not necessarily indicate higher integration of the European RES innovation system is that the result on increased intensity of knowledge flows may simply mirror an increase in collaborative patenting between any two EU15 countries, which would enhance cross-border citations merely due to increased collaboration. As already mentioned in Section 3, roughly $8 \%$ of RES patents in our sample are "multiple-country" patents as a consequence of having inventors from different countries. This could be the case because each inventor innovates by building on previous knowledge, which is largely domestic. An increase in "multiplecountry" patents over time could then naturally give rise to more cross-country citations, as the cooperating inventors cite each other's previous knowledge. ${ }^{20}$

Integration across the European RES technology space would imply an increasing intensity of cross-country citations beyond what would simply originate from increasing cross-country co-patenting. We thus formulate the following

Hypothesis 4. Reliance of each European country on the knowledge base of other European countries increases after 2000 beyond what results from direct cross-country collaborations:

$\phi_{E U 15, \text { nat }}^{\text {no_coll }} \leq 0 \quad$ and $\quad \phi_{E U 15, \text { otherEU }}^{\text {no_cll }}>0$

where coefficients are estimated from Eq. (3) after dropping from our

\footnotetext{
${ }^{20}$ This does not include self-citations, rather citations to other domestic patents which are part of each inventor's knowledge stock.
}

sample all patents which are the results of cooperation between two or more countries.

Lastly, a third reason why Hypothesis 2 may not necessarily indicate higher integration of the European RES innovation system is that a greater propensity to source from the neighbours' knowledge in Europe after 2000 could just originate from an increase in the quality of European research output rather than a reduced fragmentation of the RES knowledge base in the EU. Put it differently, our bilateral coefficients $\left(\alpha_{i j}\right)$ and shifters $\left(\phi_{i j}\right)$ result from attributes of both the citing and cited patents: the propensity of the citing patent to cite (use) external knowledge and the quality of the knowledge embedded in the cited patent. Quite likely, the two effects operate together. We then further modify our model to account for this and estimate:

$$
\begin{aligned}
& p_{i T j t}=\alpha_{T} \alpha_{t} \alpha_{i j}\left[1+\phi_{i j}^{\text {cited } *} D_{2000}^{\text {cited }}\right]\left[1+\phi_{i j}^{\text {citing } *} D_{2000}^{\text {citing }}\right] \exp \left[-\beta_{1}(T-t)\right] \\
& \quad\left(1-\exp \left[-\beta_{2}(T-t)\right]\right)+\varepsilon_{i T j t}
\end{aligned}
$$

where $\mathrm{D}_{2000}^{\text {cited }}$ is a dummy variable equal to 1 if the cited patent has priority date 2000 or after. The implicit assumption in model (3) was that $\phi_{i j}^{\text {cited }}=0, \forall i, j$, that is model (3) abstracts from changes in the propensity to being cited (which is a function of the quality of the knowledge embedded in the cited patents).

If a positive shift in the propensity of a random EU15 patent to cite a random patent from a different EU15 country $\left(\phi_{E U 15, \text { otherEU }}>0\right)$ in Eq. (3) just results from an increase in the quality of EU patents after 2000, then it should be that $\phi_{E U, \text { otherEU }}^{\text {cited }}>0$ and $\phi_{E U, \text { otherEU }}^{\text {citing }}=0$. If instead after 2000 there is an increase in the propensity of EU patents to cite other EU patents beyond any hypothetical increase in their quality, then the positive and significant sign of $\phi_{E U, \text { otherEU }}^{\text {citing }}$ should survive in the model. We can then formulate:

Hypothesis 5. After 2000, integration of knowledge bases within EU increases, ceteris paribus:

$\phi_{E U, \text { otherEU }}^{\text {citing }}>0$

We estimate Eqs. (2)-(4) by non-linear least squares. Since the model is heteroskedastic (the dependent variable is an empirical frequency), we weight each observation by the reciprocal of the estimated variance $\sqrt{\left(N_{i T}\right)\left(N_{j t}\right)}$ (see e.g. Jaffe and Trajtenberg, 1999; Popp, 2006; Bacchiocchi and Montobbio, 2010).

\section{Results}

The full set of results relative to the estimation of Eqs. (2)-(4) on our sample of RES patents are reported in Appendix B (in Supplementary material). The tables therein show the parameters $\alpha_{i j}$ and $\phi_{i j}$, as well as estimates of $\beta_{1}$ and $\beta_{2}$ for comparison with the existing literature. ${ }^{21}$ In all specifications, estimates for $\beta_{1}$ are in line with previous works, while those for $\beta_{2}$ are larger than those obtained in other studies using USPTO data, but consistent with the results in Pillu and Koléda (2011), who use EPO data.

Henceforth we focus our attention on presenting the estimates of $\alpha_{i j}$ and $\phi_{i j}$, which are more directly linked to each of the hypotheses stated in Section 4. Importantly, recall from the previous Section that each $\alpha_{i j}$ has to be interpreted as the relative probability of citation between country $i$ and country $j$, as compared to the probability that a US inventor cites a US inventor $\left(\alpha_{U S, U S}=1\right)$, while $\phi_{i j}$ indicates if and how the probability of citation between any couple of countries has changed starting from 2000, as compared to that of the US $\left(\phi_{U S, U S}=0\right)$.

Table 4 presents estimates of the likelihood of citation between any couple of countries $\left(\alpha_{i j}\right)$ over the full sample period, i.e. assuming

\footnotetext{
${ }^{21}$ Since the set of $\alpha, \phi$ and $\beta$ parameters is quite large, the tables do not report estimates for the coefficients of the cited and citing time dummies. Complete regression results are available upon request.
} 
Table 4

Regression Results, Hypothesis 1.

Model 1

Citing country

\begin{tabular}{llll}
\cline { 2 - 3 } Cited country & US & EU15 & JP \\
\hline US & 1 & $0.279^{* * *}$ & $0.262^{* * *}$ \\
& & $(0.013)$ & $(0.014)$ \\
EU15 & $0.315^{* * *}$ & $0.384^{* * *}$ & $0.140^{* * *}$ \\
& $(0.013)$ & $(0.013)$ & $(0.007)$ \\
JP & $0.470^{* * *}$ & $0.170^{* * *}$ & $0.814^{* * *}$ \\
& $(0.027)$ & $(0.008)$ & $(0.038)$ \\
\hline
\end{tabular}

Model 2

Citing country

\begin{tabular}{llll}
\cline { 2 - 3 } Cited country & US & EU15 & JP \\
\hline US & 1 & $\begin{array}{l}0.280^{* * *} \\
(0.013)\end{array}$ & $\begin{array}{l}0.264^{* * *} \\
(0.014)\end{array}$ \\
EU15 & $\begin{array}{l}0.314^{* * *} \\
0.013)\end{array}$ & $\begin{array}{l}0.140^{* * *} \\
(0.007)\end{array}$ \\
EU15 (national) & & $0.582^{* * *}$ & \\
EU15 (other EU) & & $(0.022)$ & \\
JP & & $0.299^{* * *}$ & \\
& $0.469^{* * *}$ & $0.011)$ & $0.170^{* * *}$ \\
& $(0.027)$ & $(0.008)$ & $(0.038)$ \\
\hline
\end{tabular}

Notes: see columns 1 and 2, Table B1, Appendix B (in Supplementary material) for the full set of model results. ${ }^{* * *}$ Significant at $1 \%$ level; $* *$ Significant at $5 \%$ level; *Significant at $10 \%$ level. Recall that $\mathrm{H}_{0}$ on the parameter $\alpha_{i j}$ is $\alpha_{i j}=1$, while $\mathrm{H}_{0}$ on the parameter $\phi_{i j}$ is $\phi_{i j}=0$.

$\phi_{i j}=0$, as in Eq. (2). ${ }^{22}$ Model (1) does not distinguish between EU citations to national patents and citations made to patents from other members of the EU, while model (2) estimates separate effects for national $\left(\alpha_{E U 15, \text { nat }}\right)$ vs. international $\left(\alpha_{E U 15, \text { otherEU }}\right)$ citations. As stated in Hypothesis 1, comparing these coefficients provides insights on the geographical localization of EU RES knowledge flows over the whole period and thus allows to characterize the degree of fragmentation of the EU15 RES innovation space.

These first two models provide support for Hypothesis 1, namely that the fragmentation of the European RES innovation system is indeed high. On the one hand, knowledge flows within the EU15 are weaker than in the US and Japan. Specifically, inventors from any of the EU15 countries are $38 \%$ as likely to cite another inventor from a EU15 country as compared to a US inventor citing another domestic patent $\left(\alpha_{E U 15, E U 15}=0.38\right)$. The corresponding likelihood for domestic citations of a Japanese inventor is $81 \%\left(\alpha_{J P, J P}=0.81\right){ }^{23}$ Second, any EU15 member is almost twice as likely to cite itself as opposed to citing any other EU member or the US. Indeed, in model (2) $\alpha_{E U 15, \text { nat }}=0.58$, while $\alpha_{E U 15, \text { otherEU }}=0.3$ and $\alpha_{E U 15, U S}=0.28$, the last two coefficients suggesting that EU15 inventors are basically as likely to benefit from spillovers from the US as they are to benefit from spillovers from other EU countries. By contrast, the US relies more on domestic knowledge as compared to the other countries in the sample, but it also builds more on the shoulders of the foreign giants.

In addition to suggesting a high fragmentation of the EU RES innovation system, our results also show that the likelihood of a EU15 patent to be a source of knowledge for a foreign inventor is lower than that of a US or Japanese patent. In particular, the US seems to benefit

\footnotetext{
${ }^{22}$ These results are presented in Table B1 (in Supplementary material), columns 1 and 2 .

${ }^{23}$ The high values of the bilateral coefficients $\alpha_{i j}$ when $i=j=U S$ or $i=j=J P$ are in line with previous findings (see e.g. Jaffe and Trajtenberg, 1999; Bacchiocchi and Montobbio, 2010).
}

relatively more from knowledge produced in Japan than in the EU: the likelihood of a US patent citing a Japanese one is $47 \%$, while that of citing a EU patent is $31 \%$. Along the same lines, a Japanese patent is $26 \%$ as likely to cite a US patent, but only $14 \%$ as likely to cite a EU15 patent.

Finally, note that the Japanese RES innovation space emerges as extremely self-referenced. The likelihood of a Japanese patent citing previous domestic innovation is almost as high as that of the US. In addition, we find a very low likelihood of Japanese patents citing previous patents by either US or EU15 inventors.

Table 5 presents estimation results for Eq. (3), where we allow the likelihood of citation to differ for patents applied for after 2000 ( $\phi$ coefficients). ${ }^{24}$ Table 5 confirms the results reported in Table 4 for the pre-2000 period and highlights two notable changes since 2000 , which support our Hypothesis 2. First, as regards the EU, the likelihood of domestic citation, which is $65 \%\left(\alpha_{E U 15, \text { nat }}\right)$ before 2000 , drops to $57 \%$ after $2000\left(\alpha_{E U 15, \text { nat }} *\left(1+\phi_{E U 15, \text { nat }}\right)\right)$. Second, the likelihood of citing other EU15 inventors increases from $25 \%\left(\alpha_{E U 15, \text { otherEU }}\right)$ to $31 \%$ $\left(\alpha_{E U 15, \text { other } E U^{*}}\left(1+\phi_{E U 15, \text { otherEU }}\right)\right)$. In growth terms, the percentage decrease in the probability of domestic citation was more than compensated by the increase in the probability of citation to other EU15 countries $\left(\phi_{E U 15, \text { nat }}=-0.13 ; \phi_{E U 15, \text { otherEU }}=0.25\right)$.

Overall, Table 5 supports our hypothesis that the reliance of each European country on the knowledge base of other European countries increased starting from 2000. Also in this case, further insights can be gained. First, knowledge flows to the EU15 from the US and Japan further decreases since 2000. Specifically, the probability of a EU15 inventor citing a US patent drops from $31 \%$ to less than $27 \%$, and the probability of citing a Japanese patent goes from $21 \%$ to $16 \%$. Second, the likelihood that EU15 inventors are a source of knowledge for US inventors goes from $26 \%$ before 2000 to $33 \%$ since 2000 . This represents a $25 \%$ increase since the turn of the century.

Table 6 presents the results of the estimation of Eq. (3) when considering Germany separately from other EU14 countries (see also Appendix B, Table B2 in Supplementary material). We find that, before 2000, an inventor from any EU14 country was about 2.5 times more likely to cite a national patent compared to US inventors. The corresponding likelihood of domestic citation for Germany is $44 \%$. This stark difference between Germany and other EU14 countries indicates that inventors in most national RES innovation systems in Europe predominantly build on local knowledge. Since EU14 countries were less innovative than the US, Germany or Japan over this period, the high coefficient associated with national citations for EU14 countries suggests that overall Europe was far away from the technological frontier. Furthermore, in the first part of the sample period, EU14 countries sourced relatively little from abroad, especially from other EU14 countries. Indeed, the probability that any EU14 inventor cites an innovation from another EU14 country or from Germany is lower than that of citing a US inventor (27 and $22 \%$ as opposed to $46 \%$ ). This, taken together with the high coefficient for national citations within the EU14 noted above, is again a strong indication that the EU14 innovation system was highly fragmented.

Since 2000, EU14 countries display trends similar to those highlighted in the EU15 aggregate regressions. On the one hand, they show a significant reduction in the probability of domestic citation (as well as that of citation to US inventions, the latter being larger than the former). On the other hand, the probability of cross-country/within EU14 citation increases, as does the probability that a German inventor cites a EU14 patents, and the magnitude of these effects are

\footnotetext{
${ }^{24}$ Table B1 in Appendix B (in Supplementary material) shows the $\phi_{i j}$ coefficients estimated considering the EU only as citing country, or only as cited country, or as both the citing or the cited country. The different models are estimated to show the robustness of results to changes in the specification. Since all results are strongly consistent across specifications, here we report and comment only the full model (column 5).
} 
Table 5

Regression Results, Hypothesis 2.

\begin{tabular}{|c|c|c|c|c|c|c|}
\hline \multirow[b]{3}{*}{ Cited country } & \multicolumn{6}{|c|}{ Citing country } \\
\hline & \multicolumn{3}{|c|}{$\alpha_{i j}$} & \multicolumn{3}{|c|}{$\Phi_{\mathrm{ij}}$} \\
\hline & US & EU15 & JP & US & EU15 & JP \\
\hline US & 1 & $\begin{array}{l}0.314^{* * *} \\
(0.025)\end{array}$ & $\begin{array}{l}0.264^{* * *} \\
(0.014)\end{array}$ & 0 & $\begin{array}{l}-0.135^{*} \\
(0.078)\end{array}$ & \\
\hline EU15 & $\begin{array}{l}0.264 * * * \\
(0.020)\end{array}$ & & $\begin{array}{l}0.170^{* * * *} \\
(0.015)\end{array}$ & $\begin{array}{l}0.245^{* *} \\
(0.104)\end{array}$ & & $\begin{array}{l}-0.220^{* * *} \\
(0.079)\end{array}$ \\
\hline EU15 (national) & & $\begin{array}{l}0.655^{* * *} \\
(0.044)\end{array}$ & & & $\begin{array}{l}-0.133^{* *} \\
(0.065)\end{array}$ & \\
\hline EU15 (other EU) & & $\begin{array}{l}0.246^{* * *} \\
(0.019)\end{array}$ & & & $\begin{array}{l}0.251^{* *} \\
(0.101)\end{array}$ & \\
\hline JP & $\begin{array}{l}0.468 * * * \\
(0.027)\end{array}$ & $\begin{array}{l}0.213^{* * *} \\
(0.022)\end{array}$ & $\begin{array}{l}0.816^{* * *} \\
(0.039)\end{array}$ & & $\begin{array}{l}-0.233^{* * *} \\
(0.086)\end{array}$ & \\
\hline
\end{tabular}

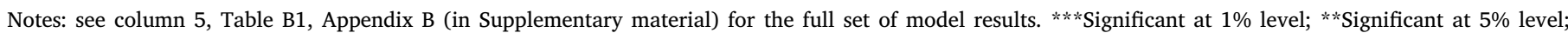
*Significant at $10 \%$ level. Recall that $\mathrm{H}_{0}$ on the parameter $\alpha_{i j}$ is $\alpha_{i j}=1$, while $\mathrm{H}_{0}$ on the parameter $\phi_{i j}$ is $\phi_{i j}=0$.

Table 6

Regression results, Hypothesis 3.

\begin{tabular}{|c|c|c|c|c|c|c|c|c|}
\hline \multirow[b]{3}{*}{ Cited country } & \multicolumn{8}{|c|}{ Citing country } \\
\hline & \multicolumn{4}{|l|}{$\alpha_{i j}$} & \multicolumn{4}{|l|}{$\Phi_{\mathrm{ij}}$} \\
\hline & US & $\mathrm{DE}$ & EU14 & JP & US & $\mathrm{DE}$ & EU14 & JP \\
\hline US & 1 & $\begin{array}{l}0.193^{* * * *} \\
(0.017)\end{array}$ & $\begin{array}{l}0.462^{* * * *} \\
(0.044)\end{array}$ & $\begin{array}{l}0.264 * * * \\
(0.014)\end{array}$ & 0 & $\begin{array}{l}0.201 * \\
(0.122)\end{array}$ & $\begin{array}{l}-0.324^{* * *} \\
(0.074)\end{array}$ & \\
\hline $\mathrm{DE}$ & $\begin{array}{l}0.220 * * * \\
(0.022)\end{array}$ & $\begin{array}{l}0.435^{* * *} \\
(0.032)\end{array}$ & $\begin{array}{l}0.221 * * * \\
(0.027)\end{array}$ & $\begin{array}{l}0.199 * * * \\
(0.024)\end{array}$ & $\begin{array}{l}0.221 \\
(0.136)\end{array}$ & $\begin{array}{l}-0.008 \\
(0.081)\end{array}$ & $\begin{array}{l}0.247 \\
(0.162)\end{array}$ & $\begin{array}{l}-0.307^{\text {*** }} \\
(0.093)\end{array}$ \\
\hline EU14 & $\begin{array}{l}0.307^{* * *} \\
(0.031)\end{array}$ & $\begin{array}{l}0.247^{* * *} \\
(0.024)\end{array}$ & & $\begin{array}{l}0.133^{* * *} \\
(0.017)\end{array}$ & $\begin{array}{l}0.312^{* *} \\
(0.146)\end{array}$ & $\begin{array}{l}0.281^{* *} \\
(0.138)\end{array}$ & & $\begin{array}{l}-0.032 \\
(0.142)\end{array}$ \\
\hline EU14 (national) & & & $\begin{array}{l}2.449 * * * \\
(0.207)\end{array}$ & & & & $\begin{array}{l}-0.222^{* * *} \\
(0.074)\end{array}$ & \\
\hline EU14 (other EU) & & & $\begin{array}{l}0.273^{* * *} \\
(0.028)\end{array}$ & & & & $\begin{array}{l}0.287^{* *} \\
(0.142)\end{array}$ & \\
\hline JP & $\begin{array}{l}0.466 * * * \\
(0.027)\end{array}$ & $\begin{array}{l}0.231^{* * *} \\
(0.027)\end{array}$ & $\begin{array}{l}0.189 * * * \\
(0.027)\end{array}$ & $\begin{array}{l}0.816^{* * *} \\
(0.039)\end{array}$ & & $\begin{array}{l}-0.265^{* * *} \\
(0.092)\end{array}$ & $\begin{array}{l}-0,166 \\
(0.126)\end{array}$ & \\
\hline
\end{tabular}

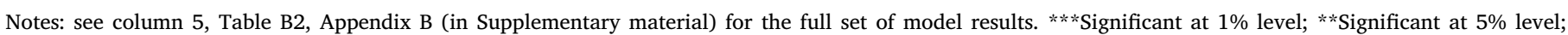
*Significant at $10 \%$ level. Recall that $\mathrm{H}_{0}$ on the parameter $\alpha_{i j}$ is $\alpha_{i j}=1$, while $\mathrm{H}_{0}$ on the parameter $\phi_{i j}$ is $\phi_{i j}=0$.

comparable. Furthermore, note that the US appears to be more likely to cite EU14 countries but not Germany. All in all, the results in Table 6 confirm that the increasing intensity of knowledge flows across European countries in RES technologies after 2000 is not driven by Germany.

We now move to considering if our results are simply driven by an increase in multi-country patenting. To do this, we drop all patents with "multiple-country" inventors and re-estimate Eq. (3) on the sample of patents with "single-country" inventors. Results are presented in Table 7 and show that Hypothesis 4 is confirmed.

Finally, Table 8 presents the results of the estimation of Eq. (4), which includes the additional term $\left[1+\phi_{\mathrm{ij}}^{\text {cited }} * D_{2000}^{\text {cited }}\right]$ controlling for changes in the quality of post-2000 patents, i.e. in their propensity to be cited. Once again, the estimates for the $\alpha_{i j}$ parameters are in line with those presented above. The inclusion of the terms $\left[1+\phi_{\mathrm{ij}}^{\text {cited } *} \mathrm{D}_{2000}^{\text {cited }}\right]$ slightly changes the magnitude of the previous estimates for $\phi_{i j}$, which have to be compared here to $\phi_{\mathrm{ij}}^{\text {citing }}$. Most importantly for our analysis, the estimated change in the term $\phi_{E U 15, \text { otherEU }}$ slightly decreases, but maintains its sign and significance $\left(\phi_{\mathrm{EU}, \text { otherEU }}^{\text {citing }}=0.19\right)$. This suggests that, in line with Hypothesis 5, the increase of knowledge flows to EU patents after 2000 is partly due to an increase in the quality of EU inventions ( $\phi_{\text {otherEU }}^{\text {cited }}>0$ ), but also effectively captures a lowering of the fragmentation in the EU RES knowledge space.

In this last model, the negative estimate of $\phi_{E U 15, \text { nat }}^{\text {citing }}$, combined with the positive and significant estimate of $\phi_{E U 15, \text { nat }}^{\text {cited }}$, suggests a peculiar pattern in EU domestic inventions. Specifically, post-2000 EU patents are relatively less likely to cite domestic pre-2000 patents, but relatively more likely to cite post- 2000 national patents. This indicates that for domestic inventors, post-2000 domestic patents are more useful than pre-2000 national patents.

The patterns of RES knowledge flows and localization discussed so far give rise to the important insight that the EU RES innovation space is becoming more integrated, with international citations between European countries becoming more important, and national citations less relevant. This effect is not driven by Germany, nor by the increase in multi-country patenting, and is not solely the result of an increase in the quality of EU patents. Furthermore, we show that the EU has increased its role as source of knowledge for the US. Nevertheless, even accounting for the post-2000 decrease in fragmentation, they also indicate that the RES innovation base at the EU level is still considerably more fragmented with respect to the US and Japanese systems. Indeed, after 2000 a citation between an EU inventor and a fellow national is $49 \%$ as likely as a citation between two US nationals, while a citation between an EU inventor and any other non-national EU inventor is roughly $29 \%$.

One last concern regarding our results is that these trends in the fragmentation of the EU innovation space may not be specific to RES, but rather common to other energy or radically new technologies. If so, this would weaken the conjecture of increasing integration being the likely result of intense and consistent environmental and energy policy efforts in the EU over the recent past. We address these questions in 
Table 7

Regression results, Hypothesis 4.

\begin{tabular}{|c|c|c|c|c|c|c|}
\hline \multirow[b]{3}{*}{ Cited country } & \multicolumn{6}{|c|}{ Citing country } \\
\hline & \multicolumn{3}{|l|}{$\alpha_{i j}$} & \multicolumn{3}{|l|}{$\Phi_{\mathrm{ij}}$} \\
\hline & US & EU15 & JP & US & EU15 & JP \\
\hline US & 1 & $\begin{array}{l}0.253^{* * *} \\
(0.021)\end{array}$ & $\begin{array}{l}0.247^{* * *} \\
(0.014)\end{array}$ & 0 & $\begin{array}{l}-0.107 \\
(0.085)\end{array}$ & \\
\hline EU15 & $\begin{array}{l}0.237^{* * *} \\
(0.019)\end{array}$ & & $\begin{array}{l}0.163^{* * *} \\
(0.016)\end{array}$ & $\begin{array}{l}0.227^{* *} \\
(0.110)\end{array}$ & & $\begin{array}{l}-0.297^{* * *} \\
(0.077)\end{array}$ \\
\hline EU15 (national) & & $\begin{array}{l}0.565^{* * *} \\
(0.040)\end{array}$ & & & $\begin{array}{l}-0.040 \\
(0.076)\end{array}$ & \\
\hline EU15 (other EU) & & $\begin{array}{l}0.202^{* * *} \\
(0.013)\end{array}$ & & & $\begin{array}{l}0.379 * * * \\
(0.099)\end{array}$ & \\
\hline JP & $\begin{array}{l}0.449 * * * \\
(0.026)\end{array}$ & $\begin{array}{l}0.199 * * * \\
(0.021)\end{array}$ & $\begin{array}{l}0.786^{* * *} \\
(0.038)\end{array}$ & & $\begin{array}{l}-0.310^{* * *} \\
(0.079)\end{array}$ & \\
\hline
\end{tabular}

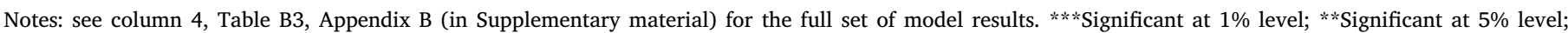
*Significant at $10 \%$ level. Recall that $\mathrm{H}_{0}$ on the parameter $\alpha_{i j}$ is $\alpha_{i j}=1$, while $\mathrm{H}_{0}$ on the parameter $\phi_{i j}$ is $\phi_{i j}=0$.

Table 8

Regression results, Hypothesis 5.

\begin{tabular}{|c|c|c|c|c|c|c|c|c|c|}
\hline \multirow[b]{3}{*}{ Cited country } & \multicolumn{9}{|c|}{ Citing country } \\
\hline & \multicolumn{3}{|l|}{$\alpha_{i j}$} & \multicolumn{3}{|l|}{$\phi_{\mathrm{ij}, \text { citing }}$} & \multicolumn{3}{|l|}{$\Phi_{\mathrm{ij}, \text { cited }}$} \\
\hline & US & EU15 & JP & US & EU15 & JP & US & EU15 & JP \\
\hline US & 1 & $\begin{array}{l}0.311^{* * *} \\
(0.025)\end{array}$ & $\begin{array}{l}0.262^{* * *} \\
(0.014)\end{array}$ & 0 & $\begin{array}{l}-0.276^{* * *} \\
(0.072)\end{array}$ & & 0 & $\begin{array}{l}0.372^{* * *} \\
(0.121)\end{array}$ & \\
\hline EU15 & $\begin{array}{l}0.262^{* * *} \\
(0.020)\end{array}$ & & $\begin{array}{l}0.169 * * * \\
(0.015)\end{array}$ & $\begin{array}{l}0.254^{* *} \\
(0.111)\end{array}$ & & $\begin{array}{l}-0.288^{* * *} \\
(0.080)\end{array}$ & $\begin{array}{l}0.014 \\
(0.077)\end{array}$ & & $\begin{array}{l}0.203^{*} \\
(0.121)\end{array}$ \\
\hline EU15 (national) & & $\begin{array}{l}0.649 * * * \\
(0.044)\end{array}$ & & & $\begin{array}{l}-0.243^{* * *} \\
(0.061)\end{array}$ & & & $\begin{array}{l}0.272^{* * *} \\
(0.088)\end{array}$ & \\
\hline EU15 (other EU) & & $\begin{array}{l}0.244^{* * *} \\
(0.019)\end{array}$ & & & $\begin{array}{l}0.185^{*} \\
(0.101)\end{array}$ & & & $\begin{array}{l}0.122^{*} \\
(0.074)\end{array}$ & \\
\hline JP & $\begin{array}{l}0.476^{* * *} \\
(0.027)\end{array}$ & $\begin{array}{l}0.211^{* * *} \\
(0.022)\end{array}$ & $\begin{array}{l}0.816^{* * *} \\
(0.039)\end{array}$ & & $\begin{array}{c}-0.138 \\
(0.109)\end{array}$ & & & $\begin{array}{l}-0.151 * \\
(0.081)\end{array}$ & \\
\hline
\end{tabular}

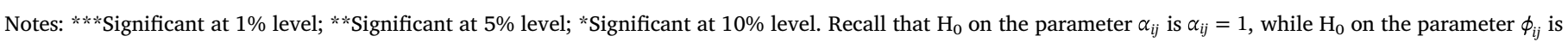
$\phi_{i j}=0$. The full set of results is available upon request.

turn in the next section. ${ }^{25}$

\section{Robustness}

We now move to testing whether the results presented for RES technologies are peculiar to this strategic field or are common to other radically new technologies. To this end, we re-estimate Eq. (3) for fossil-based technologies as well as for other radically-new technologies.

\subsection{Knowledge spillovers in highly efficient fossil-based technologies}

In a first robustness exercise, we consider the highly efficient fossil energy technologies studied in Lanzi et al. (2011). Fossil-based technologies allow producing energy by burning oil, coal or gas in stationary plants. ${ }^{26}$ These technologies represent the back-bone of the world energy system: the share of fossil fuels in the global energy mix

\footnotetext{
${ }^{25}$ As a final robustness check, we also tested the sensitivity of our results to the choice of the cut-off point. We show that all our key findings still hold when the end of the first period changes from 1999 to 1997, i.e. the year of the Kyoto Protocol and the Commission White Paper on renewable sources. Furthermore, our results hold when considering the EU27 countries as opposed to EU15 countries. All these regressions are available upon request.

${ }^{26}$ Note therefore that transport technologies are excluded from this sample.
}

amounted to $81 \%$ in 2013 (IEA, 2015a). The use of fossil fuels as main sources of energy is indeed the main reason behind rising carbon emissions worldwide. In an effort to reduce both energy dependency from fossil-exporting countries (and in particular gas and oil exporters) and anthropogenic emissions, countries have promoted two complementary strategies. On the one hand, governments promoted the development and deployment of RES, as previously mentioned. On the other hand, they strove to increase the efficiency of fossil-based technologies, which also results in lower carbon intensity.

Highly-efficient fossil technologies are a cheap medium-term option to address climate and energy security concerns. They significantly reduce emissions per unit of energy in the short-to-medium term and, contrary to the case of RES, they do not imply a significant shift in the energy system. ${ }^{27}$ Their short-to-medium-term potential makes them very attractive, and many countries provided significant support to their development. This, for instance, was true for the US, partly due to the strength of the fossil fuels lobby. This has also been the strategy of Japan since 1973, leading this country to have the lowest rate of energy

\footnotetext{
${ }^{27}$ In particular, grid integration of RES is complicated by their variability and by the fact that production is dispersed rather than centralized. Building a carbon-free energy system based on RES thus requires significant investment in upgrading the electricity grid, as well as in complementary technologies that compensate for the variability of RES. See Carrara and Marangoni (2017) and Verdolini et al. (2018) for a thorough discussion on these issues.
} 
Table 9

Regression Results: Efficient Fossil-based Technologies.

\begin{tabular}{|c|c|c|c|c|c|c|}
\hline \multirow[b]{3}{*}{ Cited country } & \multicolumn{6}{|c|}{ Citing country } \\
\hline & \multicolumn{3}{|l|}{$\alpha_{i j}$} & \multicolumn{3}{|l|}{$\Phi_{\mathrm{ij}}$} \\
\hline & US & EU15 & JP & US & EU15 & JP \\
\hline US & 1 & $\begin{array}{l}0.334 * * * \\
(0.025)\end{array}$ & $\begin{array}{l}0.358^{* * *} \\
(0.033)\end{array}$ & 0 & $\begin{array}{l}0.081 \\
(0.109)\end{array}$ & \\
\hline EU15 & $\begin{array}{l}0.345^{* * *} \\
(0.028)\end{array}$ & & $\begin{array}{l}0.242^{* * *} \\
(0.022)\end{array}$ & $\begin{array}{l}-0.212^{* * *} \\
(0.082)\end{array}$ & & $\begin{array}{l}-0.242^{* *} \\
(0.114)\end{array}$ \\
\hline EU15 (national) & & $\begin{array}{l}0.715^{* * *} \\
(0.047)\end{array}$ & & & $\begin{array}{l}-0.155^{* *} \\
(0.070)\end{array}$ & \\
\hline EU15 (other EU) & & $\begin{array}{l}0.278^{* * * *} \\
(0.018)\end{array}$ & & & $\begin{array}{l}-0.100 \\
(0.078)\end{array}$ & \\
\hline JP & $\begin{array}{l}0.376^{* * *} \\
(0.027)\end{array}$ & $\begin{array}{l}0.291 * * * \\
(0.029)\end{array}$ & $\begin{array}{l}1.509 * * * \\
(0.097)\end{array}$ & & $\begin{array}{l}0.173 \\
(0.154)\end{array}$ & \\
\hline
\end{tabular}

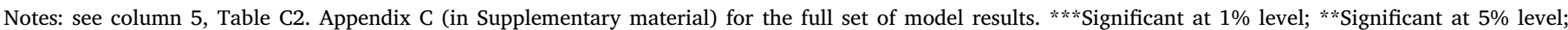
*Significant at $10 \%$ level. Recall that $\mathrm{H}_{0}$ on the parameter $\alpha_{i j}$ is $\alpha_{i j}=1$, while $\mathrm{H}_{0}$ on the parameter $\phi_{i j}$ is $\phi_{i j}=0$.

use per unit of produced GDP as compared with other industrialized nations (Takase and Suzuki, 2011).

Hence, in our specific case, these technologies represent an interesting comparison to test if the developments we described in the previous section are peculiar to RES or, rather, common to other energy generation technologies. As in Lanzi et al. (2011), ${ }^{28}$ the efficient fossil technologies we consider here include all the technologies which have significantly improved the efficiency of fossil fuel burning for energy production, namely Integrated Gasification Combined Cycle, Improved Burners, Combined Heat and Power, and such. Altogether, our sample includes 9577 patents in fossil-based technologies: 5641 from EU15, 2564 from the US and 1372 from Japan. Fig. C1 in Appendix C (in Supplementary material) shows that patent applications in fossil-fuel technologies have grown at a slower pace compared to RES and Table $\mathrm{C} 1$ does not display any sign of increasing cross-country citations within EU.

The full set of results of the estimation for efficient fossil technologies are presented in Appendix C, Table C2 (in Supplementary material). As shown in columns 1 and 2, over the whole sample period, knowledge flows in fossil energy technologies within the EU appear weaker than those within the US and within Japan, similarly to what found in RES. ${ }^{29}$ By contrast, international knowledge flows to the EU from US and Japan are higher than in the case of RES, and comparable to those received by other EU inventors. Specifically, overall EU15 countries are as likely to cite a US patent as a Japanese inventor, and roughly as likely to cite a Japanese patent as a US inventor.

Focusing on changes in knowledge spillovers patterns since 2000, which are reported in Table $9,{ }^{30}$ note that national knowledge flows in fossil technologies within EU15 members became less likely, with a decrease roughly comparable to that discussed in the case of RES. However, differently from RES, there is no evidence of any increase in cross-country/within EU15 citation intensity for fossil technologies ( $\phi_{E U, o t h e r E U}$ is both negative and not significant in all specifications). Furthermore, since 2000 the likelihood that a US or a Japanese inventor cites a EU15 patent decreased by 21 and 24\%, respectively. All these results show striking differences with respect to RES and point, if anything, to a weakening of the EU positioning with respect to the technological frontier in fossil energy technologies while showing no

\footnotetext{
${ }^{28}$ The list of IPC codes used to select patents for fossil-based technologies is provided in Appendix A2 (in Supplementary material).

${ }^{29}$ Indeed, for Japan this result is more pronounced than in RES: the probability of citing domestic fossil patents is at least $50 \%$ above the same probability for the US, indicating that Japan relies on domestic knowledge even more than in the case of RES.

${ }^{30}$ Table 9 presents the results of column 5 in Table C2.
}

sign of higher interconnectedness between the national knowledge bases of member states.

\subsection{Knowledge spillovers in radically new technologies}

We now compare knowledge flows in RES technologies to the patterns characterizing other radically new fields. Along the lines of Dechezleprêtre et al. (2014), we identify the following radically new and emerging technologies, namely 3D, IT, biotechnologies and robots. ${ }^{31}$ Our aim is to assess whether the results obtained for RES also characterize other technologies at an early stage of development and with high economic potential. Some descriptive statistics for these radically new technologies are presented in Appendix D (in Supplementary material) in order to provide a comparison with our RES technologies along two different aspects: (i) innovation levels, growth and localization; (ii) citation changes since 2000 .

These radically new technologies are quite heterogeneous in terms of innovation levels and geographical distribution of innovation across the three geographical areas relevant for our analysis. The number of EPO applications ranges from 2889 patents in 3D technologies to 184,345 in IT over the sample period (Table D1 in Appendix D in Supplementary material). The EU15 accounts for the majority of patents in each technology, but this is the result of a home-bias associated with the use of EPO patents, which we already discussed. In all cases, however, the share of EU15 patents in our sample is well below the corresponding one in RES. Interestingly, all these radically new technologies exhibit growth patterns comparable to that of RES, before 2000 (Fig. D1), but since 2000, robot and 3D technologies show an increasing trend, just like RES, while biotechnology and IT patents level off.

Focusing on raw citation frequencies (Table D2), similarly to RES, 3D technologies show an increase in citations across EU countries and a decrease in national citations; robot technologies and IT patents show an increase in both national citations and citations to other EU countries; biotechnologies show an increase in national citations and a decrease in citations to other EU patents. In all radically new technologies, the fraction of US citations directed to EU patents increases since 2000, particularly so in robot technologies.

The descriptive evidence presented above shows that RES share

\footnotetext{
${ }^{31}$ See Appendix A3 (in Supplementary material) for a list of relevant IPC used for the selection of patents. It could be argued that nanotechnologies are a clearly new and emergent field, which should be included in our comparison. While this is surely the case, we have to exclude it from our comparison exercise since the number of nanotechnology patents in our sample is still extremely low and does not allow convergence in our econometric model.
} 
some features with other radically new technologies, but that the overall picture is quite articulated and no common overall pattern emerges. We now turn to estimating Eq. (3) for each of these new technologies, considering both the specification with country-pair coefficients for the entire period and the specification with the $\phi_{i j}$ coefficients for the country-pairs in which EU15 is either citing or cited. Results are presented in Table D3.

As expected, we find evidence of heterogeneity across these technologies in the intensity of citation over the entire estimation period, but some important common features emerge. In particular, the highest coefficients are those for domestic citations, confirming the strong localization effect widely documented in the literature (Jaffe and Trajtenberg, 1999). However, when considering changes in citation patterns since 2000, none of these technologies replicate the results obtained with RES technologies. In particular, despite the previous descriptive evidence, no significant change emerges in the probability of US inventors citing EU inventors, and also the probability of EU inventors citing patents from other EU countries remains unchanged (3D and Robot technologies) or even decreases (IT and Biotechnologies). These results confirm that the patterns we found in RES technologies are peculiar and not common to other emerging technologies with substantial growth prospects. Interestingly, our results complement those of Dechezleprêtre et al. (2014), which studied the magnitude of outgoing knowledge spillovers for RES vs fossilbased technologies. They find that renewables, although resulting in larger knowledge spillovers than fossil-based technologies, are comparable to other new technologies such as those listed above. However, their analysis does not describe any geographical pattern.

\section{Discussion and conclusions}

The achievement of deep emission reductions and the promotion of a sustainable energy system are among the top priorities of European countries. In this context, innovation in clean technologies is considered a cornerstone of any successful decarbonization pathway, as it will allow to lower the cost of alternative sources of energy while promoting economic growth and strenghtening the competitiveness of EU firms. A major concern in this respect, which has been increasingly voiced in the policy debate, is that the fragmentation of the EU innovation system is a major barrier to RES innovation in the EU, under the assumption that low knowledge flows across European countries depress opportunities for further knowledge creation. Hence, in this paper we examine patent citation patterns to shed some light on the degree of integration of the EU15 innovation system in the strategic field of renewable energy technologies and, more generally, on the degree of knowledge spillovers between top innovators (the US, Japan and the EU15).

We provide two key insights. First, the results emerging from our analysis point to some key weaknesses of the EU15 RES innovation system, which is shown to be geographically localized and highly fragmented. More specifically, inventors from any EU15 country rely more on domestic innovation than on knowledge produced from other EU15 inventors. Second, we show that the EU RES innovation space has become more integrated, with citations across EU15 countries growing in importance, while national citations becoming less relevant. The EU15 has also increased its role as source of knowledge for the US, while being less likely to source knowledge from this top innovator. Importantly, our robustness checks demonstrate that (i) these results are not driven by Germany, but rather by other EU14 countries, that (ii) they capture an increase in knowledge flows which goes above and beyond what could be expected by an increase in collaborations and that (iii) they are not merely the result of an increase in the quality of more recent EU RES innovation. Furthermore, by showing that the patterns of decreased fragmentation are peculiar to the strategic field of RES and do not apply to other comparable technologies (either from the energy field - efficient fossil-based technologies - or radically new - 3D, robot technologies, IT and biotechnologies), we provide suggestive and convincing evidence that higher integration was brought about by an intensification of the EU support for RES. This came about at the turn of the century after the signing of the Kyoto Protocol which led to the establishment of the EU-ETS and the implementation of stronger and more coordinated demand-pull measures following the 1997 White Paper. Conversely, the other two top innovators in RES technologies took a much milder stand towards supporting RES. The US mostly relied on soft measures (e.g. R\&D investments and voluntary programs) and focused in particular on improving the energy efficiency of fossil-based technologies (Carlarne, 2010; Brewer, 2014). Japan kept its long-standing preference towards supporting energy efficiency (Takase and Suzuki, 2011; Moe, 2012).

Although our results do appear as good news for the EU, they still raise an important challenge for member states. If it is accepted that the fragmentation of the RES innovation space reduces opportunities to fully benefit from innovation incentives associated with environmental policies, then EU policy makers need to recognize that fragmentation has been only moderately reduced in the period under investigation. Overall, the EU RES innovation system remains significantly more geographically localized as compared to the other two top innovators. In this respect, the boost to RES support in the form of demand-pull policies was certainly beneficial, but clearly not sufficient.

Our analysis thus highlights the urgency of introducing properly designed policy interventions to specifically promote the integration of the EU RES space. This is because addressing the issue of fragmentation in an "indirect" way through demand-pull policies clearly does not spur knowledge flows across EU countries to the scale needed. Similarly to what argued in Cantner et al. (2016), we call for the implementation of a balanced policy mix, which includes not only demand-pull policies, but also technology-push measures providing direct incentives to invest in innovative activities, as well as "systemic measures" 32 promoting knowledge flows. In this respect, our results complement those presented in Cantner et al. (2016), who focus on collaborations, by suggesting that a balanced policy mix is likely to result not only in more collaboration, but also in unintended and beneficial knowledge flows, which do not arise from the direct interaction of inventors.

The Strategic Energy Technology Plan (SET-Plan) introduced in 2008 clearly represents a step in the right direction, as do the more recent Framework Programmes of the EU, which significantly increased the share of funding for projects focusing on RES and sustainable technologies, particularly for those of collaborative nature or promoting integration and coordination across member countries. ${ }^{33}$ The SET Plan, in particular, was explicitly designed to address the fragmentation of the EU RES innovation system, and to facilitate cooperation, technology transfer and knowledge exchange. ${ }^{34}$ Indeed its

\footnotetext{
${ }^{32}$ See footnote 3 .

${ }^{33}$ Whilst energy research was a major R\&D area in FP1 (1984-87) with a share on total budget of more than $50 \%$, it more than halved from 1987 until 2006 (going from about 22\% in FP2 to 10\% in FP6). Nevertheless, the share of non-nuclear energy R\&D gained some momentum over the period (with a share of energy FP budget ranging from 10\% in FP2 to around 50\% in FP5 and FP6). This goes hand in hand with an increased relative importance of RES within EU research, ranging from about $0.3 \mathrm{M} €$ in FP2 to slightly more than $1 \mathrm{M} €$ in FP6 at constant 2004 prices (Rossetti di Valdalbero, 2010). Bointner et al. (2016) reach similar conclusions as to the pattern of RES R\&D investments both at the Community level and at the Member State level. Note however that though the EC put more effort on RES starting from FP6 and FP7, funding for renewables is still low when compared to other technologies such as life sciences, new materials or ICT.

${ }^{34}$ As noted in the introduction, the problem of fragmentation of the EU research effort is explicitly recognized in EC Communications launching the SETplan (EC, 2006b, 2007). Around that time, it became clear that the technologypush measures for RES implemented in the EU appeared to be affected by scarce alignments of objectives, with research and innovation strategies often pursued independently by the different actors and countries. As argued in Rossetti di Valdalbero (2010), this resulted in "a governance failure characterized by poor integration and coordination between various levels (regional, national, EU) and by a suboptimal allocation of resources".
} 
implementation included both technology-push measures in the form of increase direct investments in RES R\&D and innovation, as well as more systemic measures such as new European Industrial Initiatives (EIIs) and the European Research Alliance (EERA) in charge of aligning R\&D activities of different actors and establishing a joint research framework at the EU level. A direct assessment of the ability of the SET-Plan to reduce integration will have to await the availability of data. ${ }^{35}$

Our analysis also indirectly sheds light on the more general fragmentation of the EU innovation system, which goes beyond the strategic field of RES. This is apparent from the low estimates associated with knowledge flows in both fossil and radically new technologies. In light of this evidence, the call for policy intervention goes beyond the promotion of knowledge integration in the strategic field of RES. While these technologies are clearly instrumental in transitioning Europe towards the Energy Union and promoting sustainable development, reducing overall fragmentation could significantly contribute to fostering EU innovation performance also in other technological fields.

As an important caveat, we would like to highlight that our paper is concerned with fragmentation in the knowledge space under the explicit assumption, largely discussed in our contribution, that higher integration is beneficial for knowledge creation, and that knowledge creation is beneficial for economic growth and development. Indeed, this nexus may be not as obvious and direct as it seems. The example of China, which gained the largest share in solar panel production worldwide without relying on a strong innovation portfolio (at least in the early years) points to the importance of considering also other important factors affecting competitiveness, such as input prices and wages.

Finally, our analysis suggests fruitful avenues for future research. First, given the time coverage of our sample, our analysis focuses on the EU15. Understanding whether our results can be generalized to all EU27 countries would clearly contribute to a better assessment of knowledge flows dynamics. Second, extending the analysis to assess the impact of more recent policies on fragmentation would enrich our results. Both these efforts can be pursued in the near future, when the availability of more recent patent data will make it possible to capture the latest innovation dynamics, including those of the newest EU members. Third, a more detailed analysis of knowledge flows across different regions and countries of the EU would clearly enrich our results, although it would require a more flexible econometric approach.

\section{Funding}

This work was supported by MIUR (Italian Ministry for Education, University and Research) under the research programme "Climate Change in the Mediterranean Region: Evolutionary Scenarios, Economic Impacts, Mitigation Policies and Technological Innovation" (PRIN project 2010-2011) and by the Horizon 2020 research and innovation programme [grant agreement $n^{\circ} 642147$ (CD-LINKS) and grant agreement $n^{\circ} 730403$ (INNOPATHS)].

\section{Acknowledgements}

Earlier versions of this paper were presented at the Paris Environmental and Energy Economics Seminar, at the GRI Conference on Innovation and Growth, at the EAERE Conference, at the IPSDM

\footnotetext{
${ }^{35}$ Note, however, that the general perceived view is that the 2008 SET-Plan did not live up to the EC expectations in this respect. Indeed, COM(2013)253, p. 7, states that that, "although Member States do share common industrial and research objectives, their commitment to the SET Plan is currently suboptimal. Coordinated and/or joint investments between Member States and with the EU need to be fostered to leverage private sector investments in support of the EIIs Technology Roadmaps and the EERA Joint Programmes" (EC, 2013). See also Ruester et al. (2014).
}

Conference, at CONCORDi 2017, and at the 4th Geography of Innovation Conference. The authors would like to thank Laura Diaz Anadón, Matthieu Glachant, Mariagrazia Squicciarini, David Popp, and Francesco Vona as well as all the participants to seminars and conferences for insightful discussions. The authors are also grateful to two anonymous referees for helpful comments.

\section{Appendix A. Supplementary material}

Supplementary material related to this article can be found, in the online version, at doi:https://doi.org/10.1016/j.respol.2018.07.007.

\section{References}

Aghion, P., Jaravel, X., 2015. Knowledge spillovers, innovation and growth. Econ. J. 125, 533-573.

Antonelli, C., Colombelli, A., 2017. The locus of knowledge externalities and the cost of knowledge. Reg. Stud. 51 (8), 1151-1164.

Bacchiocchi, E., Montobbio, F., 2010. International knowledge diffusion and home-bias effect: do USPTO and EPO patent citations tell the same story? Scand. J. Econ. 112, $441-470$.

Balconi, M., Breschi, S., Lissoni, F., 2004. Networks of inventors and the role of academia: an exploration of Italian patent data. Res. Policy 33, 127-145.

Bointner, R., Pezzutto, S., Sparber, W., 2016. Scenarios of public energy research and development expenditures: financing energy innovation in Europe. WIREs Energy Environ. 5, 470-488.

Borghesi, S., Crespi, F., D’Amato, A., Mazzanti, M., Silvestri, F., 2015. Carbon abatement, sector heterogeneity and policy responses: evidence on induced eco innovations in the EU. Environ. Sci. Policy 54, 377-388.

Bottazzi, L., Peri, G., 2003. Innovation and spillovers in regions: evidence from European patent data. Eur. Econ. Rev. 47, 687-710.

Brahmbahatt, M., Hu, A.G.Z., 2009. Ideas and innovation in East Asia. World Bank Res. Obs. 25, 177-207.

Brewer, T.L., 2014. The United States in a Warming World. The Political Economy of Government, Business, and Public Responses to Climate Change. Cambridge University Press, New York.

Caballero, R.J., Jaffe, A.B., 1993. How high are the giants' shoulders: an empirical assessment of knowledge spillovers and creative destruction in a model of economic growth. NBER Macroeconomics Annual 1993, vol. 8.

Cantner, U., Graf, H., Herrmann, J., Kalthaus, M., 2016. Inventor networks in renewable energies: the influence of the policy mix in Germany. Res. Policy 45, 1165-1184.

Carlarne, C.P., 2010. Climate Change Law and Policy. EU and US Approaches. Oxford University Press, New York.

Carrara, S., Marangoni, G., 2017. Including system integration of variable renewable energies in a constant elasticity of substitution framework: the case of the WITCH model. Energy Econ. 64, 612-626.

Cassiman, B., Veugelers, R., 2006. In search of complementarity in innovation strategy: internal R\&D and external knowledge acquisition. Manage. Sci. 52, 68-82.

Coffano, M., Tarasconi, G., 2014. Crios-Patstat Database: Sources, Contents and Access Rules. CRIOS Working Paper no. 1.

Cohen, W.M., Levinthal, D.A., 1989. Innovation and learning: the two faces of R\&D. Econ. J. 99, 569-596.

Corsatea, T.D., 2014. Technological capabilities for innovation activities across Europe: evidence from wind, solar and bioenergy technologies. Renew. Sustain. Energy Rev. 37, 469-479.

(the) Council of the European Communities, 1986. Resolution of 16 September 1986 concerning new Community energy policy objectives for 1995 and convergence of the policies of the Member States. Off. J. Eur. Communities 29, 1-3 No C 241/1 (86/C 241/01).

De Bondt, R., 1996. Spillovers and innovative activities. Int. J. Ind. Organ. 15, 1-28.

De Bondt, R., Slaets, P., Cassiman, B., 1992. The degree of spillovers and the number of rivals for maximum effective R\&D. Int. J. Ind. Organ. 10, 35-54.

Dechezleprêtre, A., Glachant, M., Ménière, Y., 2013. What drives the international transfer of climate change mitigation technologies? Empirical evidence from patent data. Environ. Resour. Econ. 54, 161-178.

Dechezleprêtre, A., Martin, R., Mohnen, M., 2014. Knowledge Spillovers from Clean and Dirty Technologies. CEP Discussion Paper No. 1300. Centre for Economic Performance, LSE, London.

Drivas, K., Economidou, C., Karkalakos, S., Tsionas, E.G., 2016. Mobility of knowledge and local innovation activity. Eur. Econ. Rev. 85, 39-61.

Duguet, E., MacGarvie, M., 2005. How well do patent citations measure flows of technology? Evidence from French Innovation Survey. Econ. Innov. New Technol. 14, 375-393.

EC (European Commission), 1995. Green Paper on Innovation COM(95) 688 Final.

EC (European Commission), 1997. Energy for the future: renewable sources of energy. White Paper for a Community Strategy and Action Plan. COM(97) 599 Final.

EC (European Commission), 2000. Green Paper - Towards a European Strategy for the Security of Energy Supply. COM(2000) 0769 Final.

EC (European Commission), 2006a. Green Paper - A European Strategy for Sustainable, Competitive and Secure Energy. COM(2006) 105 Final.

EC (European Commission), 2006b. Communication from the Commission to the Council, 
the European Parliament, the European Economic and Social Committee and the Committee of the Regions. Towards a European Strategic Energy Technology Plan. COM(2006) 847 Final.

EC (European Commission), 2007. A European Strategic Energy Technology Plan (SETPlan). COM(2007) 723 Final.

EC (European Commission), 2010. Europe 2020 Flagship Initiative Innovation Union. $\operatorname{COM}(2010) 1161$ Final.

EC (European Commission), 2013. Communication from the Commission to the Council, the European Parliament, the European Economic and Social Committee and the Committee of the Regions: Energy Technologies and Innovation. COM(2013) 253 Final.

EC (European Commission), 2014. Communication from the Commission to the Council, the European Parliament, the European Economic and Social Committee and the Committee of the Regions: Research and Innovation As Sources of Renewed Growth. COM(2014) 339 Final.

EC (European Commission), 2015a. A Framework Strategy for a Resilient Energy Union with a Forward-looking Climate Policy. COM(2015) 80 Final.

EC (European Commission), 2015b. Towards an Integrated Strategic Energy Technology (SET) Plan: Accelerating the European Energy System Transformation. COM(2015) 6317 Final.

EEA (European Environmental Agency), 2012. Greenhouse Gas Emission Trends and Projections in Europe 2012 - Tracking Progress Towards Kyoto and 2020 Targets. EEA Report 6/2012. Copenhagen.

EEA (European Environmental Agency), 2016. Renewable Energy in Europe 2016 Recent Growth and Knock-on Effects. EEA Report 4/2016. Copenhagen. .

Fischer, M.M., Scherngell, T., Jansenberger, E., 2009. Geographic localization of knowledge spillovers: evidence from high-tech patent citations in Europe. Ann. Reg. Sci. 43, 839-858.

Garrone, P., Grilli, L., 2010. Is there a relationship between public expenditure in energy R\&D and carbon emission per GDP? An empirical investigation. Energy Policy 38, 5600-5613.

Grafström, J., 2017. International knowledge spillovers in the wind power industry: evidence from the European Union. Econ. Innov. New Technol. 27, 205-224.

Griliches, Z., 1990. Patent statistics as economic indicators: a survey. J. Econ. Lit. 28, 1661-1707.

Harhoff, D., Scherer, F.M., Vopel, K., 2003. Citations, family size, opposition and the value of patent rights. Res. Policy 32, 1343-1363.

HEAL (Health and Enviroment Alliance), 2013. The Unpaid Bill. How Coal Power Plants Make Us Sick. Available at. www.env-health.org/unpaidhealthbill.

Hu, A.G.Z., 2009. The regionalization of knowledge flows in East Asia: evidence from patent citations data. World Dev. 37, 1465-1477.

Hu, A.G.Z., Jaffe, A.B., 2003. Patent citations and international knowledge flow: the cases of Korea and Taiwan. Int. J. Ind. Organ. 21, 849-880.

IEA (International Energy Agency), 2015a. World Energy Outlook 2015. OECD/IEA, Paris.

IEA (International Energy Agency), 2015b. Energy and Climate Change: World Energy Outlook Special Report. OECD/IEA, Paris.

IEA (International Energy Agency), 2015c. World Economic Outlook - Policy Databases. https://www.iea.org/policiesandmeasures/.

Jaffe, A.B., Trajtenberg, M., 1996. Flows of Knowledge from Universities and Federal Laboratories: Modeling the Flow of Patent Citations Over Time and Across Institutional and Geographic Boundaries. NBER Working Paper n. 5712. National Bureau of Economic Research, Cambridge, MA.

Jaffe, A.B., Trajtenberg, M., 1999. International knowledge flows: evidence from patent citations. Econ. Innov. New Technol. 8, 105-136.

Jaffe, A.B., Trajtenberg, M., Henderson, R., 1993. Geographic localization of knowledge spillovers as evidenced by patent citations. Q. J. Econ. 108, 577-598.
Jaffe, A.B., Fogarty, M.S., Banks, B.A., 1998. Evidence from patents and patent citations on the impact of NASA and other federal labs on commercial innovation. J. Ind. Econ. 46, 183-205.

Jaffe, A.B., Newell, R.G., Stavins, R.N., 2005. A tale of two market failures: technology and environmental policy. Ecol. Econ. 54, 164-174.

Johnstone, N., Hascic, I., Popp, D., 2010. Renewable energy policies and technological innovation: evidence based on patent count. Environ. Resour. Econ. 45, 133-155.

Lanzi, E., Verdolini, E., Haščič, I., 2011. Efficiency-improving fossil fuel technologies for electricity generation: data selection and trends. Energy Policy 39, 7000-7014.

Lee, G., 2006. The effectiveness of international knowledge spillover channels. Eur. Econ. Rev. 50, 2075-2088.

LeSage, J.P., Fischer, M.M., Scherngell, T., 2007. Knowledge spillovers across Europe: evidence from a Poisson spatial interaction model with spatial effects. Pap. Reg. Sci. 86, 393-421.

Levin, R.C., Reiss, P.C., 1988. Cost-reducing and demand-creating R\&D with spillovers. Rand J. Econ. 19, 538-556.

Mancusi, M.L., 2008. International spillovers and absorptive capacity: a cross-country cross-sector analysis based on patents and citations. J. Int. Econ. 76, 155-165.

Maurseth, P.B., Verspagen, B., 2002. Knowledge spillovers in Europe: a patent citations analysis. Scand. J. Econ. 104, 531-545.

Moe, E., 2012. Vested interests, energy efficiency and renewables in Japan. Energy Policy 40, 260-273.

Nicolli, F., Vona, F., 2016. Heterogeneous policies, heterogeneous technologies: the case of renewable energy. Energy Econ. 56, 190-204.

Noailly, J., Shestalova, V., 2017. Knowledge spillovers from renewable energy technologies: lessons from patent citations. Environ. Innov. Soc. Transit. 22, 1-14.

OECD, 2012. Energy and Climate Policy. Bending the Technological Trajectory. OECD Studies in Environmental Innovation, Paris.

Park, W.G., 1998. A theoretical model of government research and growth. J. Econ. Behav. Organ. 34, 69-85.

Peri, G., 2005. Determinants of knowledge flows and their effect on innovation. Rev. Econ. Stat. 87, 308-322.

Pillu, H., Koléda, G., 2011. Determinants of innovation in efficient and renewable energy technologies. Economie \& prévision 197-198, 105-128.

Popp, D., 2005. Lessons from patents: using patents to measure technological change in environmental models. Ecol. Econ. 54, 209-226.

Popp, D., 2006. International innovation and diffusion of air pollution technologies: the effects of $\mathrm{NO}_{\mathrm{x}}$ and $\mathrm{SO}_{2}$ regulation in the US, Japan and Germany. J. Environ. Econ. Manage. 51, 46-71.

Rossetti di Valdalbero, D., 2010. The Power of Science: Economic Research and European Decision-Making: The Case of Energy and Environment Policies. Peter Lang Pub Inc.

Ruester, S., Schwenen, S., Finger, M., Glachant, J.M., 2014. A post-2020 EU energy technology policy: revisiting the strategic energy technology plan. Energy Policy 66, 209-2017.

Sung, H.Y., Wang, C.C., Chen, D.Z., Huang, M.H., 2014. A comparative study of patent counts by the inventor country and the assignee country. Scientometrics 100 , 577-593.

Takase, K., Suzuki, T., 2011. The Japanese energy sector: current situation, and future paths. Energy Policy 39, 6731-6744.

Verdolini, E., Bosetti, V., 2017. Environmental policy and the international diffusion of cleaner energy tecnologies. Environ. Resour. Econ. 66, 497-536.

Verdolini, E., Galeotti, M., 2011. At home and abroad: an empirical analysis of innovation and diffusion in energy technologies. J. Environ. Econ. Manage. 61, 119-134.

Verdolini, E., Vona, F., Popp, D., 2018. Bridging the gap: do fast reacting fossil technologies facilitate renewable energy diffusion? Energy Policy 116, 242-256.

Wu, C., Mathews, J.A., 2012. Knowledge flows in the solar photovoltaic industry: insights from patenting by Taiwan, Korea, and China. Res. Policy 41, 524-540. 